\title{
Calculo da massa total do sangue.
}

\author{
por
}

Octavio Magalhães.

( Com 2 ifiguras no texto e estampas 7 e 8.)

\section{Berechnung der Gesamtblutmenge.}

von

Octavio Magalhães.

( Mit 2 Text figuren und Tafeln 7 u. 8.)

Calcular a massa total do sangue contido no aparelho circulatorio tem constituido vasto campo de estudos em fiziolojia.

$E$ nem de outro modo mesmo deveria ser tratado um problema, de cuja solução dependem magnas questões de medicina.

E' tal, porém, a soma de empecilhos a romper, e as cauzas de erro a eliminar, que se pode afirmar, não haver um unico processo impassivel de objeção.

Daí, a disparidade de rezultados obtidos, ainda quando em mãos experimentadas, muitos dos quais em frizante contradição e rebeldia. E' o cazo de achar LAHOUSSE para a massa total sanguinea do coelho $1 / 18$ e COLIN 1/31 do pezo do corpo. Para o boi
Die Berechnung der im Circulationsapparat enthaltenen Gesamtblutmenge ist immer ein weites Feld fuer die physiologische Forschung gewesen.

Es konnte dies bei einem Problem, mit dessen Loesung bedeutende medizinische Fragen verknuepft sind, auch nicht anders sein. Es gilt jedoch hier, eine solche Menge von Hindernissen aus dem Wege zu raeumen und soviele Fehlerquellen zu beseitigen, dass man keck behaupten kann, es existiere kein einziges einwandfreies Verfahren. So erklaert sich die Verschiedenheit in den erlangten Resultaten selbst bei geschulten Untersuchern, von denen viele in offenem Widerspruch zu einander stehen. So z. B. fand LAHOUSSE beim Kaninchen eine Gesamtblutmenge von $1 / 18$ und COLIN von 1/31 des Koerpergewichtes. COLIN stellte 
achava COLIN 1/29 e HEISSLER 1/13; e assim por diante.

Não nos anima a idea de recapitular aqui, marcando falhas, todos os processos desde o inicial, de considerar a massa de sangue escoada pela seção dos grossos vazos, como sendo a expressão exata da massa total sanguinea, até o recente metodo clinico de GRAWITZ pelo pletismografo.

Todos esses metodos, muitos dos quais dum valor puramente historico, se encontram reunidos e comentados nos tratados comuns de fiziolojia. Não ha mister aqui reedital-os. O trabalho que hoje aprezentamos, é a primeira parte dum vasto assunto, que nos indicou o ilustre mestre Dr. OSWALDO CRUZ, e para execução do qual, tivemos a felicidade de encontrar como guia tão sabio quanto experimentado, o assistente do Instituto Dr. ALCIDES GODOY.

As perdas sanguineas, levadas a certo ponto, acarrretam fatalmente a morte do individuo.

Ainda quando socoridos a tempo os sintomas do chamado dezaguamento, a morte sobrevem inevitavel, se se transpõe um certo limite, que infelizmente, determinado de modo geral, falha de regra no cazo individual.

O soro fiziolojico só ou de parceria, terapeutica em geral das hemorrajias, se conjura o dezaguamento em muitos cazos, falha, ainda quando injetado em dozes maximas, em outros. E' que o fator de dezaguamento, o fator mecanico de massa, se tem importancia no mecanismo circulatorio, não constitue elemento unico de valia para seu perfeito funcionamento.

Outro ha, e não menos valiozo, reprezentado pelos vectores de oxijenio e de alimento, sem os quais a vida celular não se executa.

E' um papel complexo, que os mais perfeitos soros conhecidos não lograram ainda suprir.

E foi justamente sob esse ponto de vista, da melhor substituição das perdas san- beim Rind $1 / 29$ und HEISSLER $1 / 13$ fest u. s. w.

Es ist nicht unsere Absicht, hier saemtliche Methoden zu wiederholen und zu kritisieren, die damit beginnen, die nach Durchschneidung der grossen Gefaesse abgeflosseneu Blutmenge als den genauen Ausdruck der Gesamtblutmenge anzusehen und mit der juengsten klinischen Methode von GRAWITZ THAL mittelst des Plethysmographen enden.

Alle diese Methoden, von denen viele nur historischen Wert besitzen, finden sich aufgezaehlt und besprochen in den allgemeinen Lehrbuechern der Physiologie. Sie brauchen deshalb hier nicht wieder angefuehrt zu werden. Die gegenwaertige Arbeit ist der erste Teil einer umfangreichen These, mit deren Ausfuehrung wir von unserem verehrten Lehrer, Dr. OSWALDO CRUZ, betraut wurden und bei deren Bearbeitung wir so gluecklich waren, in der Person des Dr. ALCIDES GODOY, Assistenten des Institutes, einen kenntnisreichen und erfahrenen Fuehrer zu finden.

Der bis zu einer gewissen Hoehe gesteigerte Blutverlust zieht unausbleiblich den Tod des Individuums nach sich. Wenn auch noch zur rechten Zeit den Folgen des Fluessigkeitsverlustes begegnet wird, tritt der Tod doch unvermeidlich ein, wenn eine gewisse Grenze ueberschritten wird, die zwar im Allgemeinen feststeht, jedoch im konkreten Falle gewoehnlich nicht zutrifft.

Die gewoehnlich gegen Haemorrhagien verwandten Mittel, physiologische Salzloesung in Kombination mit anderen Zusaetzen, bekaempft zwar den Fluessigkeitsverlust in vielen Faellen, schlaegt in anderen aber selbst bei Infusion groesserer Mengen fehl. Es beruht dies darauf, dass der mechanische Faktor der Masse, obwohl er fuer den Mechanismus der Zirkulation wichtig ist, doch fuer dessen vollkommene Funktion nicht den einzigen Faktor von Bedeutung darstellt. Einen anderen, nicht minder wichtigen, repraesentieren die Sauerstofftraeger und Vermittler der Ernaehrung, ohne welche das Zellenleben nicht bestehen kann. Diese komplizierte Auf- 
guineas, por elementos capazes, não apenas de conjurar o fator dezaguamento, mas tambem de levar oxijenio e acaretar alimentos, que encetámos o nosso trabalho. Nas condições de experiencias em que nos colocámos, isto é, evitando entrar em cauza o fator massa, sangrando e injetando ao mesmo tempo, não era facil determinar num dado momento operatorio, o quanto retirado ou o quanto deixado.

E' que no fim de poucos instantes, o que saia não era apenas sangue, e sim uma mistura deste e do liquido injetado.

Seria necessario saber pois á tanto de mistura saida, quanto de sangue teria ficado.

E a noção do quanto existia ainda em sangue no animal, apoz a retirada duma certa quantidade de mistura, era condição primordial num trabalho, onde conjurar as consequencias das perdas sanguineas era objetivo vizado.

Encarando a realização das nossas experiencias, dois fatos nitidamente se impoem:

10 a constancia da massa.

20 a diluição ininterrupta da concentração inicial do sangue.

Sem que se encontre perfeitamente identicos em. qualquer outra parte, pode-se todavia divizar problemas, que se assemelhem ao feitio nos dominios da cinetica quimica.

Nós nos propomos a diluir dum modo continuo, um meio liquido - sangue - determinando a "velocidade de diluição» pelas variações do reziduo seco.

Pouco importa que a expressão «reziduo seco» rezuma aqui, não uma, mas multiplas substancias. Em ultima instancia, embora de formação complexa, o "reziduo seco» do sangue tem função duma unica substancia.

Conhecida a constante de diluição num cazo dado, não haveria mais incognitas na marcha dessa reação, e a massa inicial igno- gabe kann auch von dem besten Serum nicht geloest werden.

Bei Beginn meiner Arbeit leitete mich eben dieser Gesichtspunkt, wie man das Blut bei Verlusten durch Elemente ersetzen könnte, die nicht nur zum Ersatz der Fluessigkeit, sondern auch zur Zufuehrung von Sauerstoff und Naehrstoffen geeignet sind. Bei der von uns gewaehlten Versuchsanordnung, indem wir naemlich den Faktor der Fluessigkeitsmasse durch gleichzeitige Blutentziehung und Infusion ausschalteten, war es nicht leicht, in einem gegebenen Zeitpunkt der Op'eration zu bestimmen, wie viel entzogen oder wie viel belassen wurde, da nach Ablauf von wenigen Minuten die ausfliessende Fluessigkeit kaum mehr Blut war, sondern eine Mischung von diesem und der eingespritzten Fluessigkeit.

Es wuerde also noetig sein, an der Menge der ausgeflossenen Mischung zu erkennen, wie viel Blut im Koerper geblieben waere. Die Kenntnis der im Tiere verbliebenen Blutmenge nach Entziehung einer bestimmten Quantitaet der Mischung, waere die Grundbedingung fuer eine Arbeit, die auf $\mathrm{Be}$ kaempfung der Folgen des Blutverlustes gerichtet war.

Bei der Betrachtung der Durchfuehrung unserer Versuche, treten 2 Ergebnisse besonders deutlich hervor, naemlich:

1. Die Konstanz der Menge.

2. Die ununterbrochene Verduennung der Anfangskonzentration des Blutes.

Wenn auch anderwaerts keine voellig gleichen Probleme angetroffen werden, so kann man immerhin auf dem Gebiete der chemischen Bewegungslehre solche beobachten, die sich der Form nach aehnlich verhalten.

Wir nahmen uns vor, eine Fluessigkeit Blut - in kontinuierlicher Weise zu verduennen, wobei wir die "Geschwindigkeit der Verduennung» durch die Veraenderungen des Trockenrueckstandes bestimmten.

Es tut wenig zur Sache, dass hier der Ausdruck "Trockenrueckstand» nicht eine, sondern mehrfache Substanzen bezeichnet. Schliesslich stellt der Trockenrueckstand des 
rada seria agora perfeitamente calculavel na simplicidade duma proporção.

Caraterizemos os fatos, num exemplo simples, e vejamos como chegar a dedução da formila.

Tonnemos certa massa de solução salina, por cxemplo, e nos proponhamos diluil-a du a modo continuo, retirando de cada vez crta quantidade de solução, para logo substituida por igual quantidade d'agua distilada.

Chamemos $\frac{1}{n}$ o gráo de diluição sofrida pela massa inicial em cada substituição, o valor no fim da primeira substituição seria, reprezentando por $M$, a concentração inicial e por $m$, a atual:

$$
\mathrm{m}=M\left(1-\frac{1}{\mathrm{n}}\right)
$$

no fim da segunda

$$
\mathrm{m}=M\left(1-\frac{1}{\mathrm{n}}\right) 2
$$

e no fim de $\underline{d}$

$$
\mathrm{m}=M\left(1-\frac{1}{\mathrm{n}}\right) \mathrm{d}
$$

e assim por diante. Formando assim uma proporção geometrica decrecente. Com o crecer, porém, das substituições para a retirada duma mesma quantidade de liquido a "velocidade de diluição» vai decrecendo para um limite.

Suponhamos pois agora, que em lugar de quantidades mensuraveis em um numero finito de vezes, retiramos quantidades infinitamente pequenas num numero infinitamente grande de vezes.

A ininterrupção do processo de retirada e injeção simultaneas nos levaria fatalmente a isso e destarte a expressão (3) tornarse-ia:

$$
\mathrm{m}=M\left(1-\frac{1}{\mathrm{n} \times a}\right) \mathrm{Ld}
$$

Aqui $n$, tendendo para zero, em face de $a$, cujo valor é infinito, torna-se desprezivel,
Blutes, wenn auch zusammengesetzter Natur, in seiner Funktion eine einzige Substanz dar.

Waere die Konstante der Verduennung in einem gegebenen Falle bekannt, so wuerde es keine Unbekannten mehr im Verlaufe dieser Reaktion geben und die unbekannte anfaengliche Masse liesse sich nunmehr durch eine einfache Gleichung berechnen.

Wir wollen die Verhaeltnisse an einem einfachen Beispiele klar legen und sehen, wie wir zur Ableitung der Formel gelangen:

Wir nehmen zu diesem Zweck eine bestimmte Menge einer Salzloesung und beginnen diese fortgesetzt $\mathrm{zu}$ verduennen, indem wir jedesmal eine gewisse Quantitaet der Loesung entnehmen, die sofort durch die gleiche Menge destillierten Wassers ersetzt wird.

Nennen wir $\frac{1}{\mathrm{n}}$ den Verduennungsgrad, den die anfaengliche Menge bei jedem Wasserzusatz erfaehrt, dann haetten wir, wenn $M$ der Anfangskonzentrationsgrad und $m$ der jeweilig vorhandene ist, am Schlusse des ersten Zusatzes folgendes Resultat:

$$
\mathrm{m}=M\left(1-\frac{1}{\mathrm{n}}\right)
$$

am Schlusse des zweiten:

$$
\mathrm{m}=M\left(1-\frac{1}{\mathrm{n}}\right) 2
$$

am Schlusse der $d$

$$
\mathrm{m}=M\left(1-\frac{1}{\mathrm{n}}\right) \mathrm{d}
$$

u. s. w., und wir erhalten auf diese Weise eine absteigende geometrische Gleichung. Bei dem Ansteigen des Ersatzes fuer die gleiche herausgenommene Fluessigkeitsmenge, faellt die Verduennungsgeschwindigkeit bis zu einer bestimmten Grenze.

Setzen wir nunmehr den Fall, dass wir anstatt messbarer Mengen in endlicher Zahl unendlich kleine Mengen in unendlich grosser Zahl entnehmen, wozu der ununterbrochene Fortgang von gleichzeitiger Herausnahme und Zusatz notwendig fuehrt, so folgt daraus:

$$
\mathrm{m}=\mathrm{M}\left(1-\frac{1}{\mathrm{n} \times a}\right) \text { Ld }
$$

Nachdem $n$, wegen des unendlichen Wertes von $a$, zu Null wird, und daher vernach- 
e a expressão (4) ficaria passando ao limite:

$$
\mathrm{cu}^{\mathrm{m}}=\mathrm{Me}^{a} \mathrm{~m}^{\mathrm{e}-a^{2}}
$$

$\mathrm{Na}$ formula (5) tomando $M$ como unidade temos que

$$
\mathrm{m}=\mathrm{e}-a
$$

e para $a=1$ teriamos

$$
\mathrm{m}=\mathrm{e}
$$

Para uma massa igual a $2 \mathrm{M}$, teriamos uma velocidade de diluição $\frac{\mathrm{e}}{2}$, para que no tempo 1 fosse igual a $m$; isto é, 2 vezes menor. Se nós chamarmos $p$ o valor da massa liquida em relação a $M$, teremos a formula

$$
\mathrm{pM}=\mathrm{m} \frac{\mathrm{e}-a}{\mathrm{p}}
$$

o que expressa o asserto; "velocidade de diluição» é inversamente proporcional á massa inicial ou a massa é inversamente proporcional á "velocidade da diluição». Determlnada pois a constante de diluição num cazo, por uma simples proporção inversa, chega-se a saber a massa inicial.

Ex. : $\frac{136}{.3434}=\frac{1000}{\mathrm{x}}=2,5$

Para o calculo da velocidade de diluição ou da constante, bem como da quantidade total, servimo-nos da formula ( 6 ), que transformada para o emprego dos logaritmos de BRIGGS dá

$$
\begin{aligned}
& \log . M=\frac{\log \cdot \mathrm{m}+\log .}{a} \\
& \log . \mathrm{e}=\frac{\log \cdot \mathrm{M}-\log \cdot \mathrm{m}}{a}
\end{aligned}
$$

Integrada desse modo a formula e partindo desse raciocinio, procuramos realizar experiencias in vitro nas mesmas condições, e ajuizar dos rezultados.

Eis a tecnica: $700 \mathrm{cc}$. duma solução, á $8,2 \%$ de $\mathrm{NaCl}(0,082 \mathrm{em} 1$ cc. $)$ foram colo- laessigt werden kann, wuerde die Gleichung folgendermassen lauten:

$\underset{\text { oder }}{\mathrm{m}}=\mathrm{Me}^{a}$

$$
\mathrm{M}=\mathrm{m}^{\mathrm{e}-a}
$$

Wenn in Gleichung (5) $M$ gleich 1 ist, dann haben wir:

$$
\mathrm{m}=\mathrm{e}-a
$$

und wenn $a=1$, dann waere:

$$
\mathrm{m}=\mathrm{e}
$$

Fuer eine Menge, gleich $2 M$, haetten wir eine Verduennungsgeschwindigkeit von $\frac{\mathrm{e}}{2}$, damit diese in der Zeiteinheit gleich $m$ wuerde, d. h. 2 mal kleiner. Wenn wir $p$ den Wert der fluessigen Menge inbezug auf $M$ nennen, so bekommen wir die Formel:

$$
\mathrm{pM}=\mathrm{m} \frac{\mathrm{e}-a}{\mathrm{p}}
$$

was zu dem Satze fuehrt: Die Verduennungsgeschwindigkeit ist umgekehrt proportional der anfaenglichen Masse, oder die Menge ist umgekehrt proportional der "Verduennungsgeschwindigkeit». Ist daher die Konstante der Verduennung in einem Falle bekannt, so erhaelt man durch eine einfache umgekehrte Gleichung, den Wert der anfaenglichen Masse.

$$
\text { Beispiel: } \frac{136}{.3434}=\frac{1000}{x}=2,5
$$

Zur Berechnung der Verduennungsgeschwindigkeit oder der Konstante, sowie auch der Gesamtmenge, benuetzen wir die Formel (6), die in Logarithmenform nach BRIGGS folgendermassen lautet:

$$
\begin{aligned}
& \log \cdot \mathrm{M}=\frac{\log \cdot \mathrm{m}+\log \cdot \mathrm{e}}{a} \quad \text { ou } \\
& \log \cdot \mathrm{e}=\frac{\log \cdot \mathrm{M}-\log \cdot \mathrm{m}}{a}
\end{aligned}
$$

Nachdem die einzelnen Groessen der Formel dergestalt bestimmt wareu, suchten wir, von dem naemlichen Gedankengang ausgehend, unter den gleichen Bedingungen Untersuchungen in vitro auszufuehren und aus den Resultaten unsere Schluesse zu ziehen.

Technik: $700 \mathrm{ccm}$. einer 8,2\% \% igen Loesung von $\mathrm{NaCl}(0,082$ in $1 \mathrm{ccm}$.) kommen in 
cados num triturador de vidro, ajitado mecanicamente por um motor de ar quente (Fig. 1). eine Reibemuehle aus Glas, die durch einen Heissluftmotor mechanisch in Betrieb gesetzt wird Tex fig. 1 .

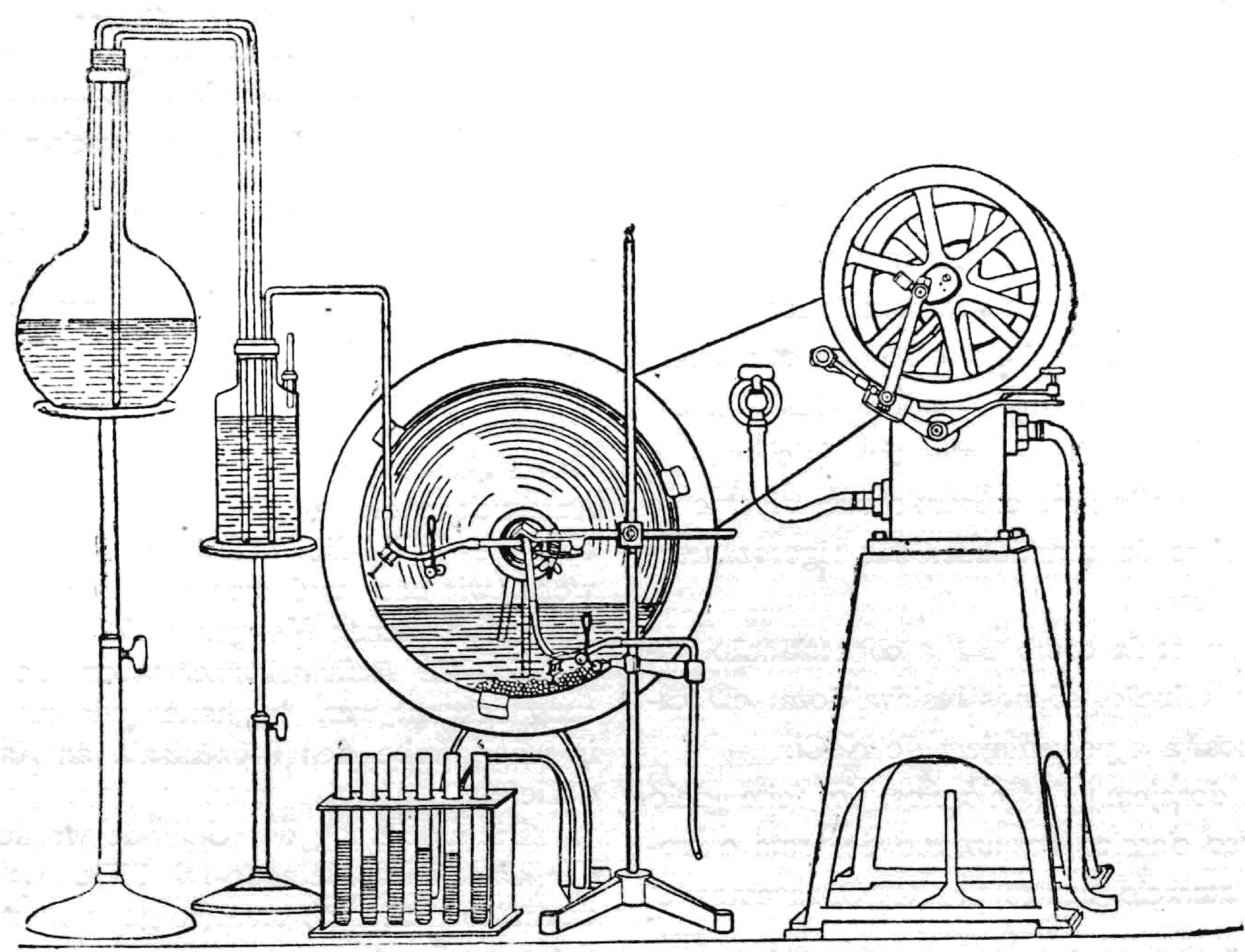

Fig. 1

Sobre o movimento uniforme e continuo havia no interior, auxiliando e melhorando as misturas, pequenas esferas massiças de vidro.

Dois tubos mantidos por um sustentaculo, penetravam pelo gargalo do triturador: um trazendo agua distilada dum frasco em plano mais elevado, cujo nivel liquido era mantido constante por um dispozitivo de MARIOTTE, penetrava apenas, na camada liquida do triturador; outro penetrava fundo na mesma camada liquida e dava saida ao conteudo do triturador, recebido, ora em tubos de ensaio, mantidos numa estante de madeira, em serie numerada para provas, ora em vazos comuns
Um eine gleichmaessige und konstituierliche Bewegung $\mathrm{zu}$ ermoeglichen und auf diese Weise zur besseren Mischung beizutragen, befinden sich im Inneren kleine massive Glaskugeln.

2 durch ein Gestell festgehaltene Rohre dringen durch den Hals der Reibemuehle: das eine, das aus einer etwas hoeher angebrachten Flasche, deren Fluessigkeitsniveau immer konstant durch eine MARIOTTE'sche Vorrichtung erhalten wird, destilliertes Wasser zufuehrt, dringt nur oberflaechlich in die Fluessigkeitsschicht der Reibemuehle; das andere Rohr taucht tief in diese Fluessigkeit ein und dient zum Austritt des Inhaltes; derselbe wird, zu spaeterer Bestimmung, entweder in Reagenzglaeschen aufgefangen, die 
para ulterior determinação. Duplo movimento pois se processava dentro do triturador; um, o da diluição pela agua distilada da solução primitiva, outro, o do escapamento da solução cada vez mais fraca. Este duplo movimento era regulado por 2 pinças de pressão adatadas ao percurso de cada tubo.

Antes de encetar a experiencia definitiva, ensaiámos, previamente, pela dispozição das pinças, uma maior ou menor obliteração dos tubos de chegada e saida, estabelecendo um otimo de operação, expresso na constancia da massa liquida do triturador. Destarte, em tais condições de experiencia, iniciámos a operação definitiva, colhendo sucessivamente 5 amostras de quantidades não rigorozamente identicas.

Conhecida como era, a concentração inicial da solução, só nos restava dozar em cada amostra a percentajem de $\mathrm{NaCl}$.

A dozajem dos cloretos, foi feita pelo processo classico do azotato de prata e cromato amarelo neutro de $\mathrm{K}$. Dozavamos 3 . vezes o mesmo estalão, e tiravamos a media O erro, quando existia, duma dozajem a outra no mesmo estalão era minimo, o que confirmava a precizão do metodo.

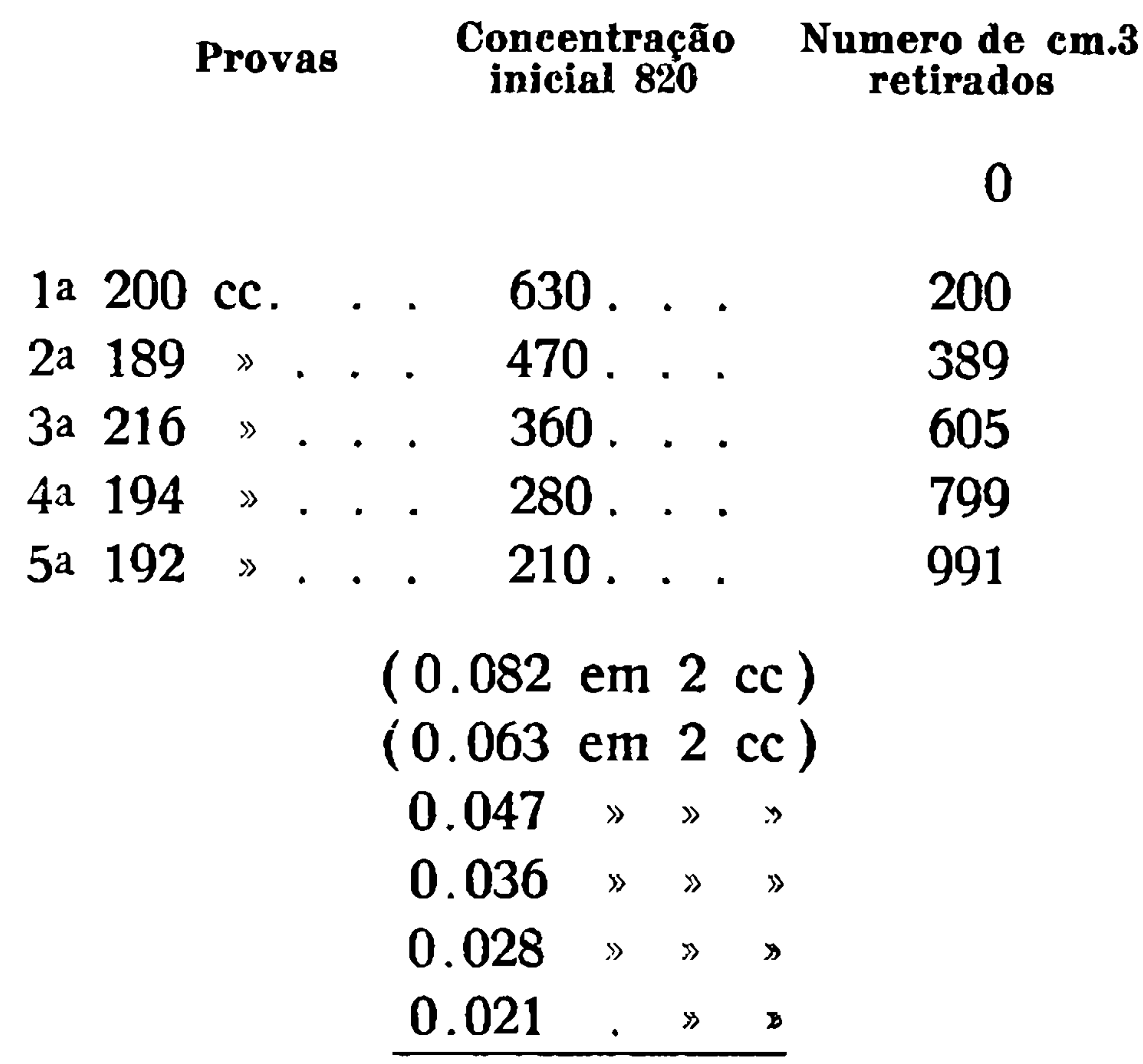

in numerierter Reihe zu Pruefungen auf ein Holzgestell kommen oder in gewoehnliche Gefaesse. Ein doppelter Vorgang spielt sich demnach im Innern der Reibemuehle $a b$ : einmal die Verduennung der urspruenglichen Loesung durch destilliertes Wasser und dann der Austritt der immer schwaecher werdenden Loesung. Dieser zweifache Vorgang wird durch 2, an jedem Rohre angebrachte, Klemmen reguliert.

Ehe wir zu dem definitiven Versuch schritten, probierten wir vorher, durch die Anlage der Klemmen eine groessere oder geringere Verzoegerung des $\mathrm{Zu}$ - und $\mathrm{Ab}$ flusses aus und stellten somit das Optimum des Versuches fest, das in der Konstanz der Fluessigkeitsmenge der Reibemuehle seinen Ausdruck fand. Auf diese Weise vorbereitet, begannen wir die definitive Ausfuehrung, wobei wir nach und nach 5 Proben von nicht genau identischen Mengen erhielten.

$\mathrm{Da}$ die Anfangskonzentration der Loesung bekannt war, so hatten wir nur mehr in jeder Probe den Prozentsatz an $\mathrm{NaCl} z u$ dozieren.

Die Dozierung der Chloride wurde nach der klassischen Methode mit Silbernitrat und neutralem Kaliumchromat vorgenommen. Wir dozierten 3 mal die gleiche Standardloesung und berechneten dann den Mittelwert. Die Fehler von einer Dosierung zur anderen, wenn ueberhaupt solche vorkamen, waren ganz unbedeutend, ein Beweis fuer die Genauigkeit der Methode.

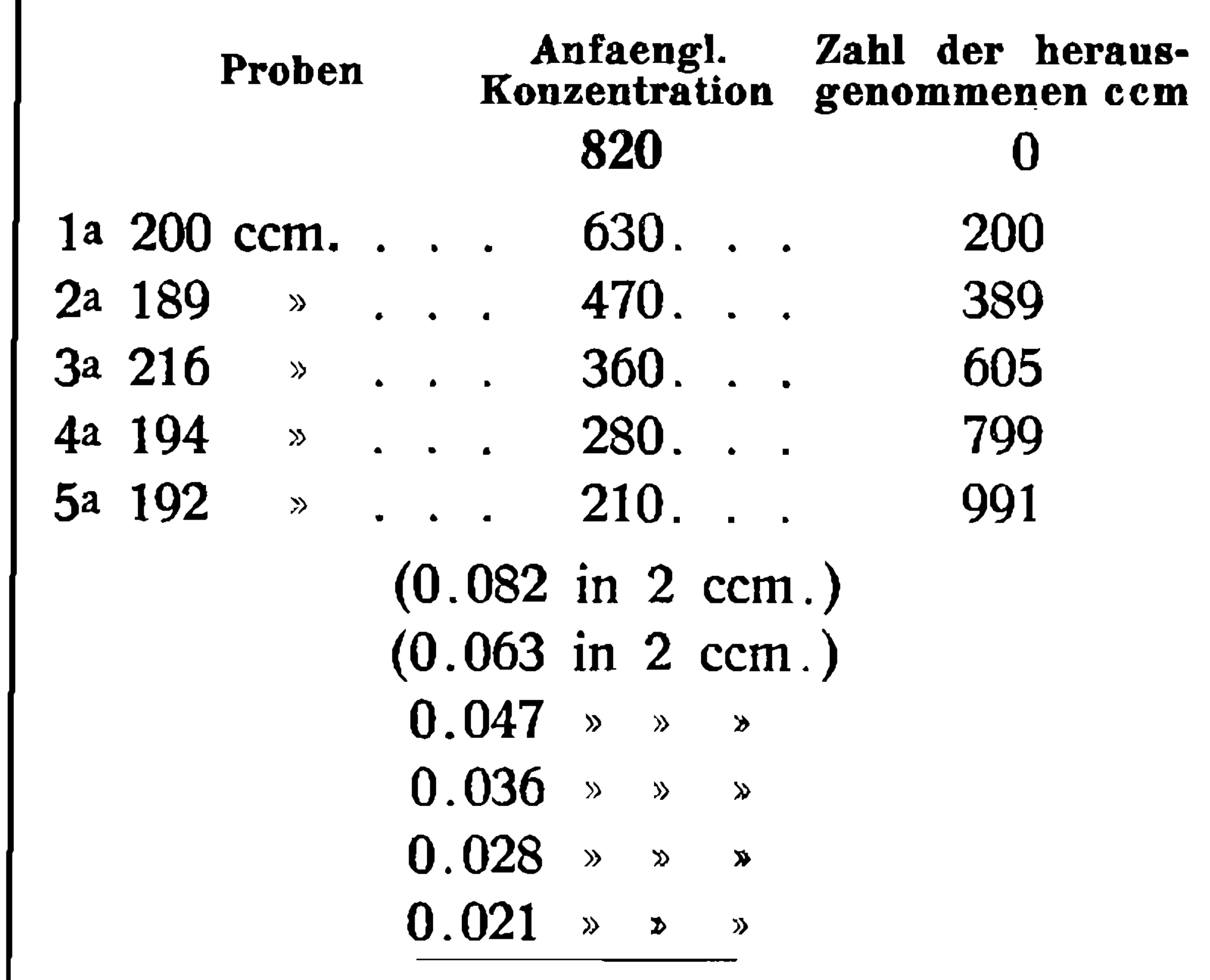


Apliquemos pois a formula e calculemos:

$\log .820=9140$

log. $630=7993$

log. $1147=0595$

log. $200=3010$

$7585 \log .=573.5$

$\log .820=9140$

log. $470=6721$

log. $2419=3836$

$\log .389=\frac{5899}{7937} \log .=\underline{621.9}$

log. $820=9140$

$\log .360=5560$

log. $3580=5538$

$\log .606=7817$

7721 log. $=\mathrm{de} 891.8$

log. $820=9140$

$\log .280=4470$

log. $4670=6693$

log. $799=9020$

$7673 \log .586$

$\log .820=9140$

log. $210=3220$

log. $5920=7723$

log. $991=9960$

7763 log. 597.5

Reconstruido o calculo:

$\log .586$

574

media 587

598

592

2350 / 4

$\begin{array}{ll}35 & 587\end{array}$

30

2
Wir uebertragen dies auf die Formel und berechnen :

$\log .820=9140$

$\log .630=\underline{7993}$

log. $1147=0595$

$\log .200=3010$ $7985 \log .=573.5$

$\log .820=9140$

log. $470=6721$

log. $2419=3836$

log. $389=\underline{5899}$ 7937 log. $=621.9$

$\log .820=9140$

log. $360=5560$

log. $3580=5538$

log. $605=7817$ 7721 log. $=\underline{591.8}$

log. $820=9140$

log. $280=\underline{4470}$

log. $4670=6693$

$\log .799=9020$ $7673 \log .586$

log. $820=9140$

$\log .210=3220$

log. $5920=7723$

log. $991=\underline{9960}$ 7763 log. 597.5

Mittelwert der erlangten Resultate :

log. 586

574

587

598

592

2350/ 4

$35 \quad 587$

30 
Erro prov.

$$
\begin{array}{rrc}
d & d^{2} & \\
13 & 196 & \text { erro medio da } \\
5 & 25 & \text { media }= \pm \sqrt{\frac{343}{12}= \pm 5} \\
1 & 1 & \\
11 & 121 & 587 \pm 5
\end{array}
$$

log. $587=7686$

log. $200=3010 \quad \log .820=9140$

$$
1 . \overline{0696} \log .-\frac{1173}{7967} \log .=62.62
$$

log. $587=7686$

$\log .389=5899 \log .820=9140$

$$
1.3585 \log .=\frac{2283}{6857} \log .=48.59
$$

$\log .587=7686$

log. $605=7899 \log .820=9140$

$$
1.5503 \text { log. }=\frac{3551}{5589} \log .=36.20
$$

$\log .587=7686$

log. $799=9020 \quad \log .820=9140$

$$
1.6706 \text { lon. }=\underline{4684} \underline{4456} \log .=27.90
$$

log. $587=7686$

$\log .991=9960 \quad \log .820=9140$

$$
\overline{.7646} \log . \quad=5816
$$

$$
3324 \log .=21.01
$$

Valor achado directamente

Valor calculado

$$
\begin{aligned}
& 82 \text {. . . . . . . } 82 \\
& 63 . . . \quad . \quad . \quad 63 \\
& 47 \text {. . . . . . . . } 48 \\
& 36 \text {. . . . . . . } 36 \\
& 28 \text {. . . . . . . . } 28 \\
& 21 . . \quad . \quad . \quad . \quad .21
\end{aligned}
$$

Conheciamos a massa inicial $(700 \mathrm{cc}$.) e a constante media da "velocidade de diluição" (587) da mesma.

Isso em condições de experiencias, que mais tarde, afóra distancias forçadas dos experimentos em «anima vili», poderiam per-
Wahrscheinlicher Fehler:

d $d^{2}$

13196 durchschnittlicher Fehler des Mittel-

$\begin{array}{rrl}5 & 25 \\ 1 & 1 \\ 11 & 121\end{array} \quad$ wertes $= \pm \sqrt{\frac{343}{12}= \pm 5}$

343

$$
587 \pm 5
$$

log. $587=7686$

$\log .200=3010 \log .820=9140$

$$
1.0696 \log .=\frac{1173}{7967} \log .=62.62
$$

$\log .587=7686$

log. $389=5899 \log .820=9140$

$$
1.3585 \log .=\frac{2283}{6857} \log . \underline{48} .59
$$

log. $587=7686$

log. $605=7817 \log .820=9140$

$$
1.5503 \log .=\frac{3551}{5589} \log .=36.20
$$

log. $587=7686$

log. $799=9020 \log .820=9140$

$$
1 . \overline{6706} \log .=\underline{4684}
$$

log. $587=7686$

log. $991=9060 \log .820=9140$

$$
\overline{.7646} \log . \quad=\underline{5816}
$$

Direkt gefun$3324 \log .=21.01$

dener Wert

\section{Berechneter} Wert

$$
\begin{aligned}
& 82 \text {. . . . . . . } 82 \\
& 63 . . . . . .63 \\
& 47 . . . \quad . \quad . \quad 48 \\
& 36 \text {. . . . . . . } 36 \\
& 28 \text {. . . . . . . . } 28 \\
& 21 . . \quad . \quad . \quad . \quad . \quad 21
\end{aligned}
$$

Die anfaengliche Menge (700 ccm.) war bekannt, ebenso die durchschnittliche Konstante der Verduennungsgeschwindigkeit derselben $=587$.

Dies trifft $\mathrm{zu}$ bei Versuchsbedingungen, die spaeter ganz gut durch aehnliche bekraeftigt werden koennten, mit Ausnahme von 
feitamente se assegurar de identicass. Poderiamos saber, tanto de mistura saida á quanto de reziduo correspondia.

Poderiamos estabelecer de outro lado uma escala cujo primeiro termo fosse 700 , em serie decrecente até zero.

Preferimos, porém, para facilidade de calculos ulteriores, estabelecer uma tabela cujo primeiro termo fosse 1000 (Vide Estampa 8).

A curva da estampa junto, é um indice por onde auferir o quanto restante num dado momento operatorio supondo 1000 a massa inicial, e conhecendo a constante da «velocidade de diluição» no cazo $=4343$, isto é o $\log$. do limite $e$.

Junto, damos tambem, o inverso dessa operação numa tabela de 1000 a zero. A coluna $\frac{1}{\mathrm{n}}$ reprezenta a serie dos numeros que devem ser multiplicados pela relação obtida na curva estabelecida para o calculo da massa inicial (vide Tabela).

Qualquer, pois, que fosse a grandeza desta em ulteriores experiencias, a redução a essa escala, nos daria, rapida e sempre proporcionalmente, quanto de sangue deixado, á tanto de mistura retirada. Rezolvemos á luz desse raciocino aplicar a formula em «anima vili».

Iniciamos as experiencias em cãis, largamente obtidos por esse Instituto.

Apoz incertezas dos primeiros trabalhos, estabelecemos a seguinte tecnica, rigorozamente seguida nos cãis e com pequenos variantes para outros animais.

Pezava-se e atentava-se a temperatura no animal. O cão açaimado era fixo á uma meza simples de madeira por um jogo de correias opostas, em decubito lateral.

O pescoço em toda extensão devia ficar completamente descoberto. Raspados perfei-
Unterschieden, die bel Experimenten «anima vili», notwendigerweise auftreten. Aus der ausgeflossenen Fluessigkeitsmischung koennten wir die Groesse des Rueckstandes entsprechenderweise folgern.

Andererseits koennten wir eine Skala aufstellen, deren hoechste Grenze 700 waere und die bis zu Null hinabstiege.

Zur Erleichterung weiterer Berechnungen jedoch stellen wir lieber eine Tabelle auf, deren Hoechstwert 1000 ist (siehe Tafel 8.).

Die Kurve der beigegeben Tafel zeigt an, wodurch in einem gegebenen Zeitpunkte der Untersuchung die rueckstaendige Menge bestimmt werden kann, unter der Voraussetzung, dass die anfaengliche Menge $=1000$ und die Konstante der "Verduennungsgeschwindigkeit» bekannt ist, im gegenwaertigen Falle gleich 4343, d. h. der Log. der Grenze 3.

Beifolgend findet sich auch der umgekehrte Prozess in einer Tabelle von $1000 \mathrm{zu}$ Null. Die Rubrik $\frac{1}{n}$ stellt die Zahlenreihe dar, die mit dem in der aufgestellten Kurve erlangten Resultat multipliziert werden muss, um die anfaengliche Menge zu berechnen (siehe Tabelle).

Welches aber auch die Groesse dieser anfaeinglicher Menge bei weiteren Versuchen waere, durch Zurueckfuehrung auf diese Skala, wuerden wir schnell und stets im Verhaeltnis aus der Menge der herausgenommenen Mischung die Quantitaet des verbliebenen Blutes berechnen kcennen. Nachdem der Gedankengang klar gelegt, beschlossen wir die Formel in "anima vili» anzuwenden.

Wir begannen die Versuche an Hunden, die dem Institute in grosser Anzahl zur Verfuegung standen. Nach einigen Unsicherheiten bei den ersten Arbeiten, kamen wir zur folgenden Technik, die bei den Hunden streng durchgefuehrt wurde und bei anderen Tieren eine Abaenderung erfuhr.

Das Tier wurde gewogen und seine Temperatur gemessen. Der gefesselte Hund wurde dann auf einem einfachen Holztisch durch eine Riemen-Vorrichtung in Rueckenlage festgeschnallt.

Der Hals soll in seiner ganzen Ausdehnung unbedeckt bleiben. Nachdem die 
tamente os pelos, e pincelado com iodo (apoz o emprego de iodo nunca mais obtivemos sequer a mais lijeira supuração) o local da operação, descobriamos á escalpelo a veia jugular externa (todo o material de operação era esterilizado, fervendo-se longamente vazos, tubos, ferros etc.) cujo percurso previamente uma lijeira compressão na baze do pescoço tinha apontado. Isto posto, esmagavamos em dupla ligadura provizoria, com pinças de PÉAN, cujas extremidades de pressão previamente tinhamos envolto em borracha, os extremos descobertos da veia. Tinhamos desse modo, um campo operatorio exangue.

Secionavamos então lonjitudinalmente em curto rasgão, a veia, e introduziamos o aparelho unico que imajinamos, de sangria e injeção simultanea (Vide fig. 2). Es-
Haare abrasiert und die freiligende Haut mit Jod bestrichen war (seitdem wir Jod gebrauchten, beobachteten wir nicht die mindeste Eiterung mehr), legten wir mit dem Messer die Jugularis externa frei, deren Verlauf vorher durch eine leichte Compression an der Halsbasis festgestellt war. (Das ganze Operationsmaterial, wie Gefaesse, Roehren, Instrumente etc., wurde vorher sterilisiert.) Hierauf legten wir an den beiden freigelegten Enden der Vene eine doppelte provisorische Ligatur mit PEAN'schen Klemmen an, deren gezaehnte Enden mit Gummi bedeckt waren. Auf diese Weise hatten wir ein voellig blutleeres Operationsfeld.

Wir machten dann eine kurze Incision in Laengsrichtung der Vene und fuehrten den von uns fuer gleichzeitige Blutentziehung und Einspritzung ausgedachten Apparat ein. (Siehe Fig. 2.). Dieser aus einer T-Röhre

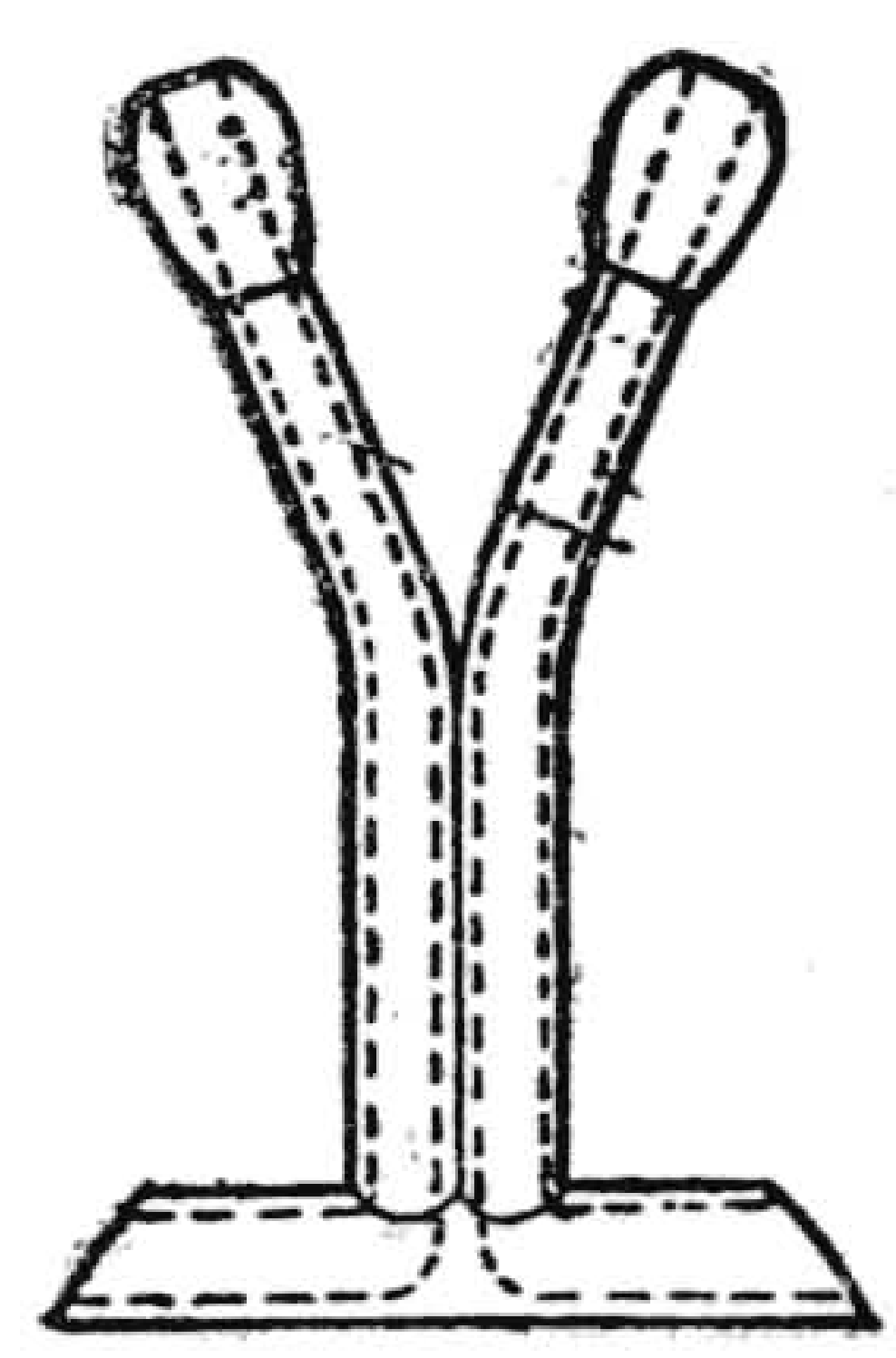

Fig. 2

te aparelho constituido por um tubo em $\mathrm{T}$ não era mais que a junção de 2 tubos rigorozamente independente em seus percursos. Um, o que olhava para a cabeça do animal, quando na veia, recebia o sangue; o outro em direção oposta trazia o liquido a injetar. Dupla ligadura por um fio de catgut, fixava o ramo hoizontal do aparelho, adatando per- bestehende Apparat war nichts anderes als der Ansatz von 2, in ihrem Verlaufe streng getrennten Schlaeuchen. Der eine, bei der Funktion des Apparates in der Vene gegen den Kopf des Tieres gerichtet, nahm das Blut auf, der andere in entgegengesetzer Richtung erhielt die einzuspritzende Fluessigkeit. Eine doppelte Ligatur mit einem Katgutfaden, hielt den horizontalen Ast des Apparates fest, an dessen Raender sich die Venenwand voellig anschmiegte. Eine sekundaere Haemorrhagie war bei Wegnahme der Klemmen 
feitamente a veia aos contornos deste. Não havia temer, quando suspensas as pinças, uma hemorrajia secundaria. Está visto, que esta operação ao todo, não excedia a $10 \mathrm{mi}$ nutos, quando atinjia.

Daí, dispensarmos qualquer anestezia. Sobre simplificar as condições de experimento, poderia talvez mais tarde ser acoimada cauza de erro ao fim que destinavamos.

Cobriamos o campo operatorio com algodão embebido numa solução de lizol $(1 \%)$.

Ligavamos a 2 tubos adrede preparados os ramos diverjentes e exteriores do aparelho em $T$. Desses ramos, um, o inferior, ficava em comunicação com um vazo contendo uma solução de $\mathrm{ClNa}$ a 8,5 0/00 perfeitamente esterilizada.

Outro, o superior, comunicava com um vazo graduado e vazio. Este era interrompido em seu percurso por uma derivação destinada a retirada das "provas», recebidas em tubos de ensaio, numerados, esterilizados e colocados num suporte de madeira.

$O$ vidro com solução fiziolojica, o vazo para receber o sangue e o suporte de madeira descançavam todos no prato dumra pequena balınça, que taravamos assim perfeitamente.

A sangria e a injeção, além disso, eram coadjuvadas por aparelhos de pressão e vacuo, e regulados por pinças, colocadas no percurso dos tubos respetivos. Só nos restava, pois, nestas condições, levantar as pinças de PÉAN colocadas na veia e dar começo á operação.

O fiel da balança nos indicava rigorozamente, si o que entrava correspondia ao que saia, em vice-versa (Estampa 7).

Dest'arte colhidas as provas, em cada cazo, conhecido o quanto retirado em cada prova, e mais, o quanto retirado ao todo, findavamos geralmente na $6^{a}$ ou 8 a prova. Cazos havia, onde chegavamos a 12a. Ligavamos então a jugular em duplo ponto, faziamos a antisepsia rigoroza do local e suturavamos com fio simples, drenando a ferida. nicht zu befuerchten. Es war sicher, dass die ganze Operation hoechstens 10 Minuten dauerte. Wir verzichteten deshalb auf jegliche Anaesthesie. Dadurch wurden die Versuchsbedingungen vereinfacht und vielleicht spaeter eine Fehlerquelle bei dem Endresultat vermieden.

Das Operationsfeld deckten wir mit in Lysolloesung (1 \%) getauchte Watte ab.

Die beiden nach aussen divergierenden Aeste des T-Apparates wurden mit 2 eigens hergerichteten Schlaeuchen verbunden. Der untere Ast kommunizierte mit einem 8,5\% \% ige Kochsalzloesung enthaltenden, voellig sterilen Behaelter. Der obere fuehrte zu einem graduierten, leeren Behaelter, und war in seinem Verlaufe durch ein Seitenrohr unterbrochen, dass zur Entnahme der Proben diente, die in nummerierten, sterilisierten, auf einem Holzgestell aufgestellten Reagenzglaesern gesammelt wurden.

Das Gefaess mit physiologischer Kochsalzloesung, der Behaelter zur Aufnahme des Blutes und das Holzgestell ruhten insgesamt in der Schale einer kleinen Wage, deren Tara auf diese Weise genau bestimmt wurde.

Die Blutentziehung und die Einspritzung wurden ueberdies unterstuetzt durch Compressions- und Vakuumapparate und reguliert durch im Verlaufe der Schlaeuche angebrachte Klemmen. Es eruebrigte demnach nur die an der Vene liegenden PÉAN'schen Arterienklemmen abzunehmen, um mit dem Versuche zu beginnen (Tafel 7).

Die Zunge an der Wage zeigte uns auf's genaueste an, ob die Menge der entzogenen Fluessigkeit der eingespritzten entsprach und umgekehrt. Nachdem so die Proben gewonnen, jedesmal die Menge der Entnahme der jeweiligen Probe und dann die Gesamtentnahme festgestellt waren, brachen wir gewoehnlich nach der 6.-8. Probe ab. In einigen Faellen gingen wir bis zu 12 Proben. Wir verschlossen hernach die Jugularis in doppelter Naht, desinfizierten das Operationsfeld und vernaehten die Hautwunde mit einfachem Faden, drainierten jedoch die Wunde 
Enr talvez 200 cazos que operamos desse modo, jamais nos ocoreu acidente algum intercurrente.

Esta tecnica tipo, seguida nos cãis, cabras, carneiros, teve variantes em outros animais. No cavalo, por exemplo, seria dificil e perigoza a aplicação do aparelho em $\mathrm{T}$ 'de injeção e sangria simultaneas. Servimo-nos então dum artifico de operação, que consistia em introduzir na mesma veia jugular, mediante distancia conveniente, 2 trocates de sangria de ROUX.

O superior era o de sangria, o inferior de injeção.

A compressão digital entre os trocates facilitava a saida do sangue pelo superior e tornava mais dificil o retorno do liquido injetado pelo inferior, já bem lonje lançado do ponto de perfuração venozo, pela introdução total na veia do trocate inferior de injeção. Dest'arte, colhiamos as provas de 500 em $500 \mathrm{cc}$. nas mesmas condições que nos outros animais.

No coelho e no gato, tambem variavam um pouco, as condições de sangria e de injeção. E' o cazo que a extrema exiguidade do calibre venozo, nos faria precindir do aparelho em $\mathrm{T}$ e abandonar as jugulares como ponto de operação. Aqui, serviamo-nos de finissimos tubos de vidro, introduzidos nas carotidas primitivas dos animais e perfeitamente adatados pelas ligaduras. Um lado recebia o liquido. As agulhas e os trocates os mais finos davam sempre rezultados imperfeitos. A sangria arterial tinha a vantajem, que não nos fornecia a venoza, de permitir retirar quantidade suficiente de sangue (mistura) para as provas respetivas. De regra, a exiguidade de calibre venozo facilitava a coagulação nas sangrias pelas jugulares.

A inoculação, na carotida, por outro lado, e não na jugular, como deveria ser, tinha
In fast 200 derartigen Versuchen kam es niemals zu einer Komplikation.

Diese typische bei Hunden, Ziegen, und Schafen befolgte Technik erfuhr bei anderen Tieren einige Abaenderung. Z. B. waere es beim Pferde schwierig und gefahrvoll, den T Apparat zur gleichzeitigen Entnahme und Einspritzung zu benutzen. Wir bedienten uns hier einer Modifikation, indem wir naemlich in die gleiche Jugularis 2 zur Punktion nach ROUX dienende Trocarts in angemessener Entfernung einstiessen. Der obere war fuer die Blutentnahme, der untere fuer die Einspritzung bestimmt.

Ein Fingerdruck auf die Vene zwischen den beiden Trokarts erleichterte den Ausfluss des Blutes aus dem oberen und verhinderte den Rueckfluss der durch den unteren eingespritzten Fluessigkeit, welche, da der untere Trocart vollstaendig in die Vene eingefuehrt wurde, ziemlich weit entfernt von der Durchbohrungsstelle einfloss. Auf diese Weise gewannen wir Proben von je $500 \mathrm{ccm}$, unter den naemlichen Bedingungen, wie bei den anderen Tieren.

Auch beim Kaninchen und der Katze wurden die Bedingungen fuer die Blutentnahme und Einspritzung etwas modifiziertWegen des aeusserst geringen Venenkalibers mussten wir hier von der Anwendung des T. Apparates abstehen und die Jugularis als Versuchsterrain aufgeben. Wir benutzten fuer solche Faelle feinste Glasroehrchen, die wir beiderseits in die carotis communis der Tiere einfuehrten und durch Ligaturen voellig mit derselben vereinigten.

Die eine Carotis communis diente zur Blutentnahme, waehrend die andere die eingespritzte Fluessigkeit aufnahm. Die Canuelen und Trocarts, selbst die allerfeinsten gaben immer unzulaengliche Resultate. Die Entnahme arteriellen Blutes hatte vor der venoesen den Vorteil, dass wir eine genuegende Blutmenge (Mischung) fuer die betr. Proben entziehen konnten. Das kleine Venenkaliber fuehrte bei der venoesen Blutentnahme leicht zur Gerinnung.

Die Einspritzung der Fliessigkeit in die Carotis der anderen Seite, und nicht, wie 
a vantajem de permitir melhor mistura intensa do liquido injetado, uma vez que a sangria era arterial e não venoza.

O liquido inoculado pela carotida fazia o mesmo vasto percurso no organismo que nos processos anteriores até chegar novamente a arteria. Não se verificava isso, nesse cazo, inoculando na jugular. Obtivemos, todavia, bons rezultados, mesmo inoculando, nessa veia. Ali, porém, duplicavam os cuidados na inoculação, para evitar a morte imediata do animal, ao menor aumento de pressão no soro á injetar. Dest'arte a massa sanguinea sempre a mesma, era diluida ininterruptamente, do inicio ao fim da operação. A mistura interna, atravez de todo o aparelho circulatorio, deveria ser completa em todos os cazos. Em uns o liquido injetado pela jugular ganhava o coração direito, ia no pulmão, vinha ao coração esquerdo, voltava aos tecidos e chegava finalmente ao ponto da saida. Noutros inoculados pela carotida ia aos tecidos vinha ao coração direito, chegava ao pulmões, voltava ao coração para tocar ao ponto de partida. Era um ciclo completo e bem vasto.

Aqui, porém, havia ainda cauza de erro a eliminar. Nós dozavamos nas provas o reziduo seco do soro. A obtenção deste era facilitada colocando os tubos na geleira.

Mas essa dozajem, feita tambem por processo orijinal, que em breve descreveremos, estava acrecida de $\mathrm{ClNa}$ da solução inoculada.

Si injetassemos agua distilada simples, restava apenas dozar o reziduo seco nas provas respetivas. Sendo isso impossivel, por motivos obvios, rezolvemos eliminar $o \mathrm{NaCl}$ das provas, para evitar erro palpavel. O soro já de si cloruretado devia aprezentar variantes diversos no correr das provas, com a inoculação de $\mathrm{NCl}$. E essas variantes impos- sonst, in die Jugularis, war in dem Sinne vorteilhaft, als sie zu einer besseren und intensiveren Mischung der eingespritzten Fluessigkeit fuehrte, da auch die Blutentnahme arteriell und nicht venoes war.

Die durch die Carotis eingespritzte Fluessigkeit legte denselben weiten Weg im Organismus zurueck, wie bei den vorhergehenden Verfahren, bis sie neuerdings in der Arterie erschien. Spritzt man jedoch anstatt in die Carotis in einem solchen Falle in die Jugularis ein, dann ist dies nicht der Fall. Doch bekamen wir auch beim Einspritzen in die Jugularis gute Resultate. Es war jedoch notwendig, hierbei die Vorsichtsmassregeln bei der Einspritzung zu verdoppeln, um den ploetzlichen Tod des Tieres bei der geringsten Drucksteigerung des eingespritzten Serums zu vermeiden. Es wurde so stets die gleiche Blutmenge ununterbrochen vom Anfange bis zum Schlusse des Versuches verduennt. Die innere, auf den ganzen Zirkulationsapparat ausgedehnte Mischung musste in allen Faellen vollstaendig sein. In den Faellen, in welchen durch die Jugularis eingespritzt wurde, floss die Fluessigkeit zuerst zum rechten Ventrikel, von da zur Lunge und dann zum linken Ventrikel, wurde dann auf der arteriellen Bahn zu den Geweben gefuehrt und kam schliesslich zum Anfangspunkt zurueck. In den anderen Faellen, in welchen die Carotis als Einflussstelle gewaehlt wurde, kam die Fluessigkeit zuerst in die Gewebe, von da zum rechten Ventrikel, dann zur Lunge und zum linken Ventrikel, von dem sie zum Ausgangspunkt zurueckkehrte; somit war der Kreislauf ein vollstaendiger und umfangreicher.

Wir mussten jedoch hierbei noch eine Fehlerquelle ausschalten. Bei den Proben dosierten wir den Trockenrueckstand des Serums, dessen Gewinnung durch Unterbringung der Reagenzroehrchen im Eiskasten erleichtert wurde. Diese, nach eigener, demnaechst zu beschreibender Methode, ausgefuehrte Dosierung ergab durch das $\mathrm{ClNa}$ der eingespritzten Loesung einen zu grossen Wert.

Haetten wir einfaches destilliertes Wasser eingespritzt, so brauchten wir nur den Trockenrueckstand bei den betreffenden Proben zu 
sivel de medir e aquilatar, já porque o $\mathrm{CINa}$ se eliminasse, já porque se fixasse de modos diferentes no organismo nos tempos diversos da operação, acarretariam, na dozajem final do soro, erro inevitavel.

Vejamos a tecnica.

Recolhidas as provas á geleira, no dia seguinte a separação do soro era perfeita. Quando em alguns tubos o soro não estava limpido e translucido centrifugavamos até a obtermos um liquido transparente. Dozavamos aí o reziduo seco. As vantajens sobre a dozajem no sangue, tivemos ocazião de verificar. Essas vantajens dizem respeito ás pezadas do rezidıo seco, e á dozajem dos cloretos.

Ambas, em sangue coagulado ou disso impedido, pela adição dum citrato, por exemplo, são duma tecnica demorada e delicada nem sempre izenta de erros. Neste ultimo cazo tinhamos ainda a alteração a eliminar na dozajem do reziduo seco pela adição dum sal. No reziduo seco, eliminavamos a evaporação das placas e a longa permanencia no forno PASTEUR. Os papeis com soro iam diretamente ao forno, e saiam prontos no fim de 15 a 30'. Com as placas nunca obtivemos um perfeito desecamento antes de 2 horas de permanencia no forno.

Nas primeiras provas, então, quando o coagulo era espesso e rezistente este tempo era insuficiente. Os cloretos dozavamos diretamente no soro.

Não havia, como no sangue a necessidade do descoramento previo por processo demorado.

Uma serie numerada de papeis de filtro (especiais para a quimica, fornecidos por CARL SCHLEICHER \& SCHUEL Pond. cineris unius filtri. I. cm. $11 \mathrm{gr}$.) com pequeno orificio numa borda, previamente pezados numa ba- dosieren. Da dies aus nahe liegenden Gruenden untunlich war, beschlossen wir, das $\mathrm{NaCl}$ aus den Proben abzuscheiden, um diesen greifbaren Irrtum zu vermeiden. Der normale Kochsalzgehalt des Serums musste durch die Einspritzung von $\mathrm{NaCl}$ im Verlaufe der Versuche verschiedene Schwankungen aufweisen.

$\mathrm{Da}$ es unmoeglich waere, diese Nuancen zu messen und abzuschaetzen, schon aus dem Grunde, weil $\mathrm{NaCl}$ sich einerseits ausscheidet und anderseits auf verschiedene Weise im Organismus waehrend der verschiedenen Zeitabschnitte der Versuche zurueckgehalten wird, wuerde bei der schliesslichen Dosierung des Serums ein unvermeidlicher Fehler sich einschleichen.

Technik:

Bei den im Eiskasten aufbewahrten Proben war am naechsten Tage das Serum vollstaendig abgeschieden. War dieses in einigen Reagenzglaesern nicht rein und durchsichtig, so zentrifugierten wir, bis die Fluessigkeit klar war. Wir dosierten dann den Trockenrueckstand, wobei wir die Vorteile gegenueber der Dosierung im Blute bestaetigt fanden. Diese Vorteile erstrecken sich auf die Gewichtsbestimmungen des Trockenrueckstandes und auf die Dosierung der Chlorsalze.

Beide Feststellungen, in geronnenem oder z. B. durch Zusatz von einem zitronensauren Salze, an der Gerinnung verhindertem Blute vorgenommen, erfordcrn eine langwierige und feine, von Fehlern nicht absolut freie Technik. In diesem Falle mussten wir noch mit der Veraenderung rechnen, welche der Zusatz eines Salzes bei der Dosierung des Trockenrueckstandes bewirkte. Beim Trockenrueckstande vermieden wir die Abdampfung der Schalen und das lange Verweilen im PASTEUR-Ofen. Der mit Serum beladene Papierfilter kam direkt in den Ofen und war nach 15-30 Minuten voellig getrocknet. Bei den Schalen erhielten wir keine vollkommene Austrocknung, bevor sie 2 Stunden im Ofen verblieben waren.

Diese Zeit genuegte nicht, wenn, wie bei den ersten Proben, das Gerinnsel dick und derb war. Die Chloride dosierten wir 
lança «CURIE» recebiam 1 cc. do soro obtido, nas diferentes provas. A pipeta completamente limpa era uma pipeta normal rigoroza. Aspiravamos ainda com a mesma pipeta em cada prova um pouco de agua distilada, para o completo carregamento do soro aderente ás paredes, e embebiamos no papel. Durante 15' a 30' esses papeis, prezos por alça de metal á bandeja dum forno PASTEUR, aí permaneciam suspensos na temperatura de $100-$ a 110 c.

No fim desse tempo o desecamento era completo. Experieneias preliminares nos provaram ser esse tempo o bastante. Conservados durante 24 h. á 370 numa estufa comum, os r ezultados não diverjiam. Não diverjem tão pouco, si em vez de 30' abandonassemos durante 4 horas ou 24 no forno PASTEUR . Eram então levados a um desecador de cloreto de calcio, e aí abandonados até o completo resfriamento. 2 horas em geral apoz' pezavamos novamente os papeis. Tinhamos o reziduo seco do soro. Excuzado seria assinalar, que durante todo esse processo, só uma pinça de extremidades envoltas numa folha de platina e perfeitamente limpa tinha contato com os papeis. Esse processo, mais pratico e com menor coeficiente de erros, era além disso mais rapido e facil. Dozavamos no soro restante das provas os cloretos.

$\mathrm{O}$ metodo seguido era o de azotato de prata e cromato neutro amarelo de potassio, processo, cuja descrição por ser demais conhecida, não faz mister transcrevel-o aqui.

Ainda quando soubessemos não ser elle um metodo absolutamente rigorozo para dozajem de cloretos, e esse ainda não surjiu em quimica, era um processo que bastava.

$\mathrm{O}$ metodo pelo permanganato de $\mathrm{K}$. e acido sulfurico, tão aconselhado com o fim de evitar cauzas de erros, expressas na prezença direkt im Serum; es war deshalb nicht, wie im Blute, eine vorhergehende Entfaerbung durch ein langwieriges Verfahren noetig.

Eine Reihe von nummerierten Papierfiltern (speziell fuer Chemie hergestellt durch CARL SCHLEICHER \& SCHUELL Pondus cineris unius filtri $=11 \mathrm{gr}$.) mit kleiner Oeffnung an einem Rande und vorher auf einer CURIE'schen Wage gewogen, wurden mit $1 \mathrm{ccm}$. des bei den einzelnen Proben erhaltenen Serums beschickt. Die dabei verwendete voellig reine Pipette war streng normal. Mit der gleichen Pipette aspirierten wir noch bei jeder Probe etwas destilliertes Wasser, um das an den Waenden anhaftende Serum voellig mit fortzuschwemmen und liessen dann damit den Filter ansaugen. Diese Filter verblieben dann 15-30 Minuten bei einer Temperatur von $100-110$ o celsius im PASTEUROfen, wo sie durch eine Metalloese an einer Einlage fixiert wurden.

Nach Ablauf dieser Zeit war die Austrocknung vollendet. Vorhergegangene Versuche liessen uns diese Zeit als ausreichend erscheinen. In einem gewoehnlichen Brutofen waren bei 370 und bei 24 Stunden Verweildauer die Resultate nicht verschieden. Ebenso war es gleichgueltig ob wir die Filter anstatt 30 Minuten 4 oder 24 Stunden im PASTEUR-Ofen aufbewahrten. Weiterhin wurden die Filter in einen Chlorcalciumexsiccator gebracht und dort bis zur voelligen Erkaltung belassen. Gewoehnlich wogen wir die Filter 2 Stunden hernach und hatten so das Gewicht des Trockenrueckstandes des Serums. Es braucht kaum ausdruecklich erwaehnt zu werden, dass: waehrend des ganzen Verfahren, nur eine, an ihren Enden mit Platin belegte und voellig reine Pinzette mit den Filtern in Beruehrung kam. Dieses, weit praktischere und weniger Fehlerquellen unterworfene Verfahren, war nebenbei auch rascher und leichter. In dem Rest der Serumproben dosierten wir die Chlorsalze.

Die hierbei befolgte Methode war die mit Salpetersaeure und neutralem chromsauren Kali, ein bekanntes Verfahren, dass der Beschreibung nicht bedarf. Zugegeben, dass diese Methode zur Dosierung der Chlor- 
de materia organica, que tentamos nas nossas experiencias, não é izento de falhas tão pouco. A demais, as diferenças de dozajem de un para outro, como pudemos verificar largamente, quando existiam, eram perfeitamente dezpreziveis. A dozajem era feita em 1 cc. rigorozamente, auxiliada a verificação da reação por um jato de luz artificial, que propozitadamente faziamos incidir sobre o campo.

Tinha a vantajem este artificio de, sobresaindo o amarelo do cromato, deixar transparecer o minimo laivo avermelhado, do termo da reação.

Faziamos 3 dozajens numa mesma prova, e a media tomavamos como rezultado. Nessas condições, deveriamos obter um rezultado favoravel, felizmente expresso nos dados que se vão seguir.

Para aqui transladaremos, porem, apenas, o que interessar estreitamente ao calculo da massa.

As perturbações manifestadas pelo animal, as diferentes peripecias morbidas no decurso da operação, não cabem neste trabalho, e talvez constituam subsidio para ulterior publicação.

O numero de cc. decorridos, supondo sempre a saida de mistura á 1 cc. por minuto, dava o tempo.

Uzavamos, porém, exceto no primeiro cão, dum pequeno artificio, que um exemplo pratico facilmente esclarecerá. Assim o quinto tempo deveria ser á soma dos $400 \mathrm{cc}$ anteriores (achando-se as provas de $100 \mathrm{em} \mathrm{100)}$ + os ce das 5 primeiras provas.

Não tomavamos, porém, a :totalidade de cc. da 5.a prova. Adotavamos um valor medio onde a dozajem deveria ter sijdo feita. Dest'arte o 50 tempo ficaria igual a soma da 400 cc. anteriormente decorridos mais os cc. salze keine absolut genaue ist, da eine solche in der Chemie noch nicht vorliegt, so ge-nuegt sie doch fuer unsere Zwecke.

Die Methode mit uebermangansaurem Kali und Schwefelsaeure ist vielfach empfohlen, um Fehlerquellen zu vermeiden, die bei zu untersuchenden organischen Substanzen, wie im unseren Falle, sich einstellen, ist aber ebenfalls nicht frei von Fehlern. Zudem konnte man die Unterschiede zwischen der einen und der anderen Dosierung ganz gut vernachlaessigen, wie wir uns - bei ev. Auftreten solcher - ueberzeugen konnten. Die Dosierung wurde exakt bis auf $1 \mathrm{ccm}$. durchgefuehrt, wobei die Feststellung der Reaktion durch einen Strahl kuenstlichen Lichtes unterstuetzt wurde, den wir in das Untersuchungsfeld fallen liessen. Dieses Verfahren hatte den Vorteil, dass der kleinste Stich von Rot, der ueber das Gelb des Chroms hervortrat, als Zeichen der Beendigung der Reaktion deutlich erkannt wurde.

Von jeder Probe machten wir 3 Dosierungen und nahmen von dem gewonnenen Resultate das Mittel. Unter solchen Umstaenden duerften wir ein guenstiges Resultat erwarten, welches in den nachfolgenden Daten gluecklicherweise zum Ausdruck kommt. Hier wollen wir jedoch nur das zur Berechnung der Blutmasse absolut Wichtige wiedergeben.

Die von Seiten des Tieres gezeigten Stoerungen, die verschiedenen krankhaften Zwischenfaelle im Verlaufe des Versuches, finden in dieser Arbeit keinen Platz und bleiben eventuell einer spaeteren Publikation vorbehalten.

Die Zahl der abgeflossenen ccm. ergab die gebrauchte Zeit, wobei wir annahmen, dass in der Minute $1 \mathrm{ccm}$. der Mischung abfloss. Ausser bei dem ersten Hunde wandten wir indessen einen kleinen Kunstgriff an, der an einem praktischen Beispiel leicht $z u$ erklaeren ist.

Wir nahmen jedoch nicht die Gesamtmenge der $\mathrm{ccm}$. der 5ten Probe, sondern einen Mittelwert der Probe, deren Dosierung vorgenommen werden sollte. Auf diese Weise waere die 5te Zeitdauer gleich der Summe 
das 4 primeiras provas e a metade e não totalidade do cc. da 5.a prova.

O mesmo para a 4.a e 3a. Das constantes obtidas em cada cazo calculavamos. $O$ erro provavel segundo a formula classica

$$
\mathrm{ep}=\frac{E^{\mathrm{d} 2}}{\mathrm{n}-(\mathrm{n}-1)}
$$

Operação

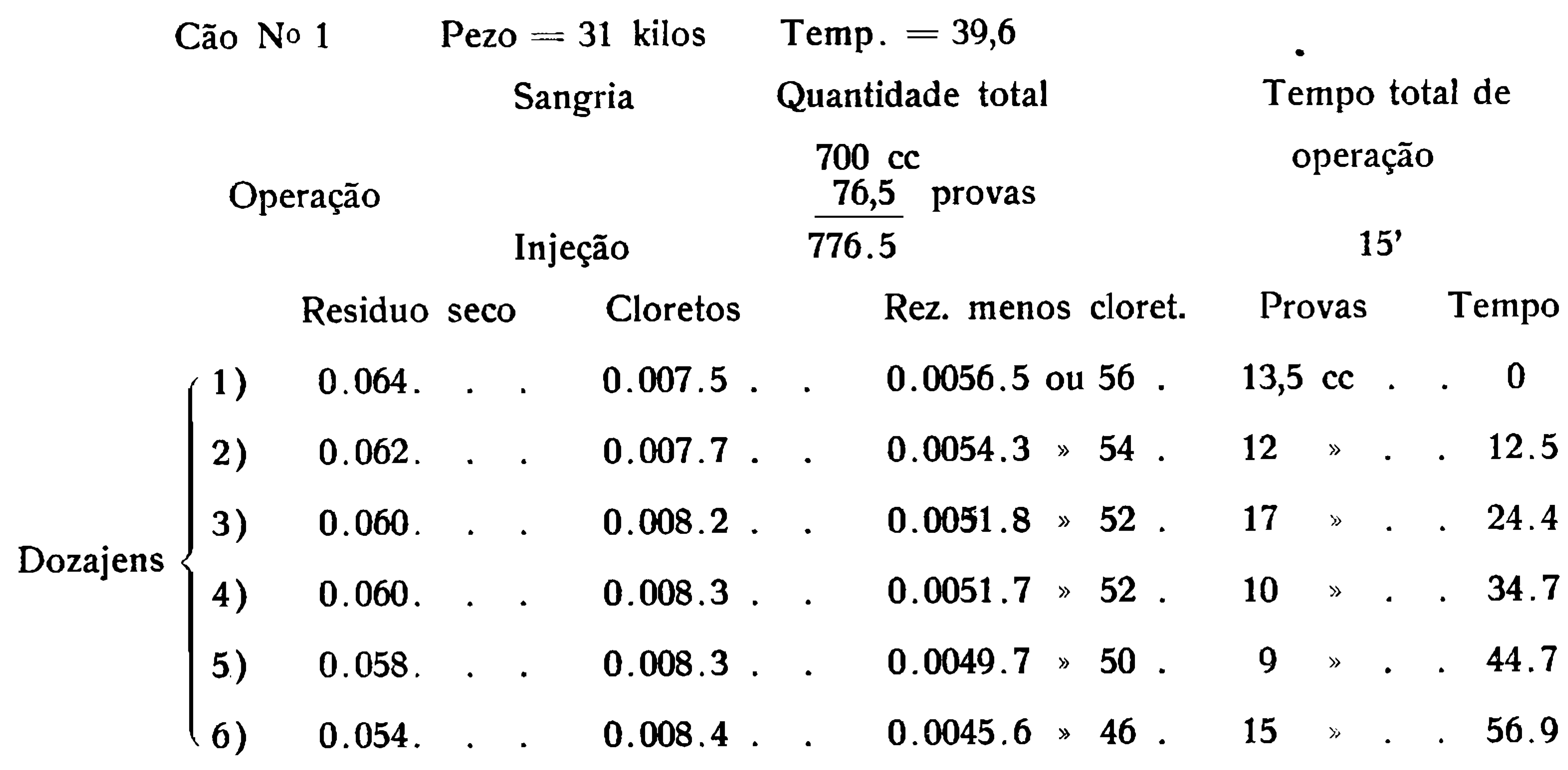

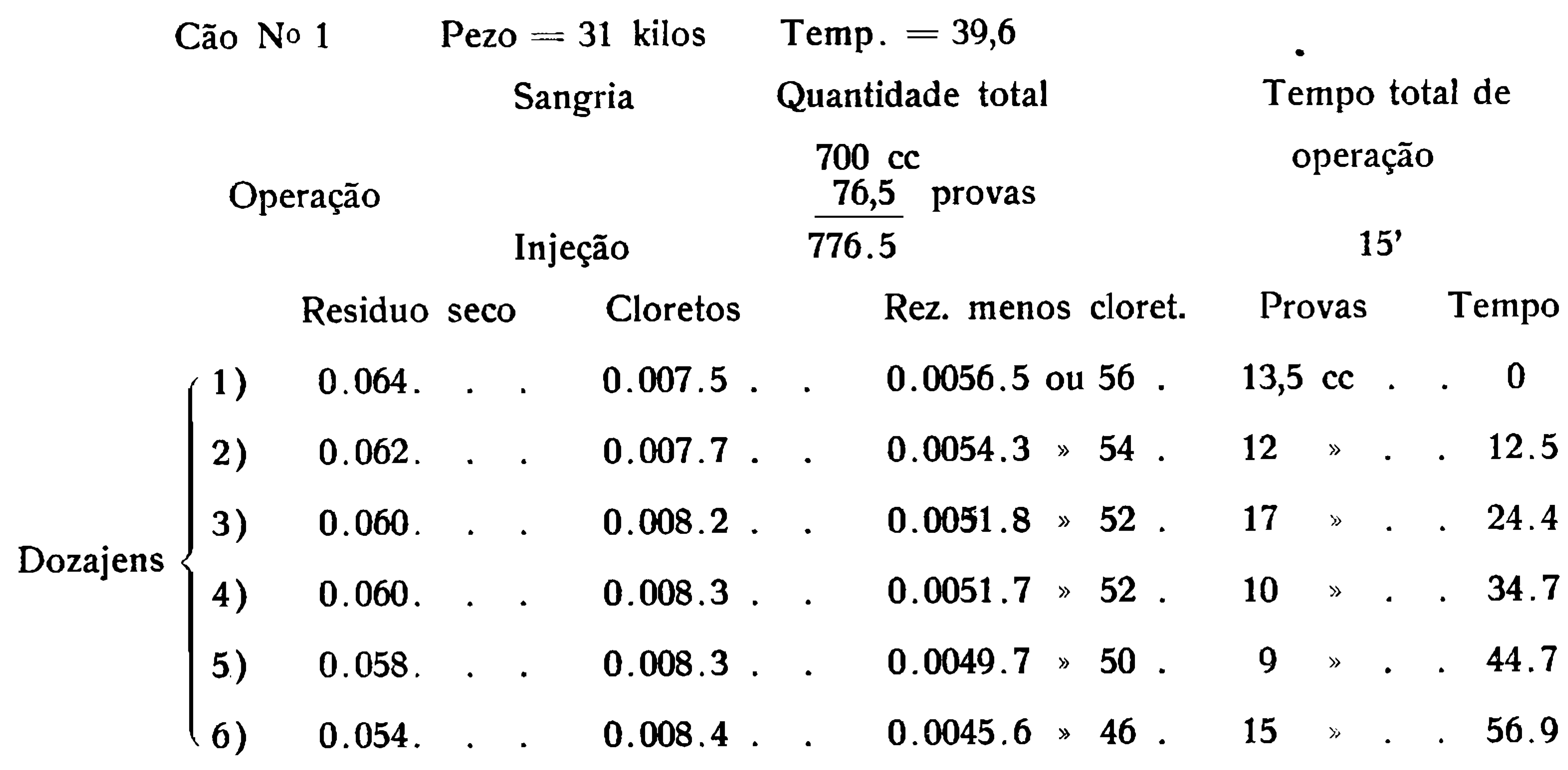

der bereits vorher abgeflossenen $400 \mathrm{ccm}$. der 4 ersten Proben plus der Haelfte, nicht der Gesamtmenge der ccm. der 5ten Probe. Dasselbe konnten wir in jedem Falle fuer die 3te und 4te bei der Probe erlangten Konstante berechnen. Der hierbei wahrscheinliche Fehler richtet sich nach der allgemein gueltigen Formel:

$$
\text { ep }=\frac{E d^{2}}{n-(n-1)}
$$

Hund No 1

Gewicht 31 Kilogr.

Blutentziehung

Versuch

Injektion

Trockenrueckstand

$$
\text { Temperatur }=39,6
$$

Gesamtmenge $700 \mathrm{ccm}$.

76,5 Proben

776,5

Chlorsalze
Rueckstand minus Proben Dauer Chlorsalze

\begin{tabular}{|c|c|c|c|c|c|c|c|c|c|}
\hline & 1) & 0.064 . & 0.007 .5 & 0.0056 .5 & de & 56 & 13,5 & $\mathrm{ccm}$. & 0 \\
\hline & 2) & 0.062 . & 0.007 .7 & 0.0054 .3 & $»$ & 54 & 12 & $»$ & 12,5 \\
\hline & 3) & 0.060 . & 0.008 .2 & 0.0051 .8 & $»$ & 52 & 17 & $»$ & 24,4 \\
\hline & 4) & 0.060 & 0.008 .3 & 0.0051 .7 & $»$ & 52 & 10 & $»$ & 34,7 \\
\hline & 5) & 0.058 & 0.008 .3 & 0.0049 .7 & $»$ & 50 & 9 & $»$ & 44,7 \\
\hline & 6) & 0.054 . & 0.008 .4 & 0.0045 .6 & $»$ & 46 & 15 & » & 56,9 \\
\hline
\end{tabular}

Gesamtdauer des Versuches /

$15^{\prime}$ 
Cão No 1.

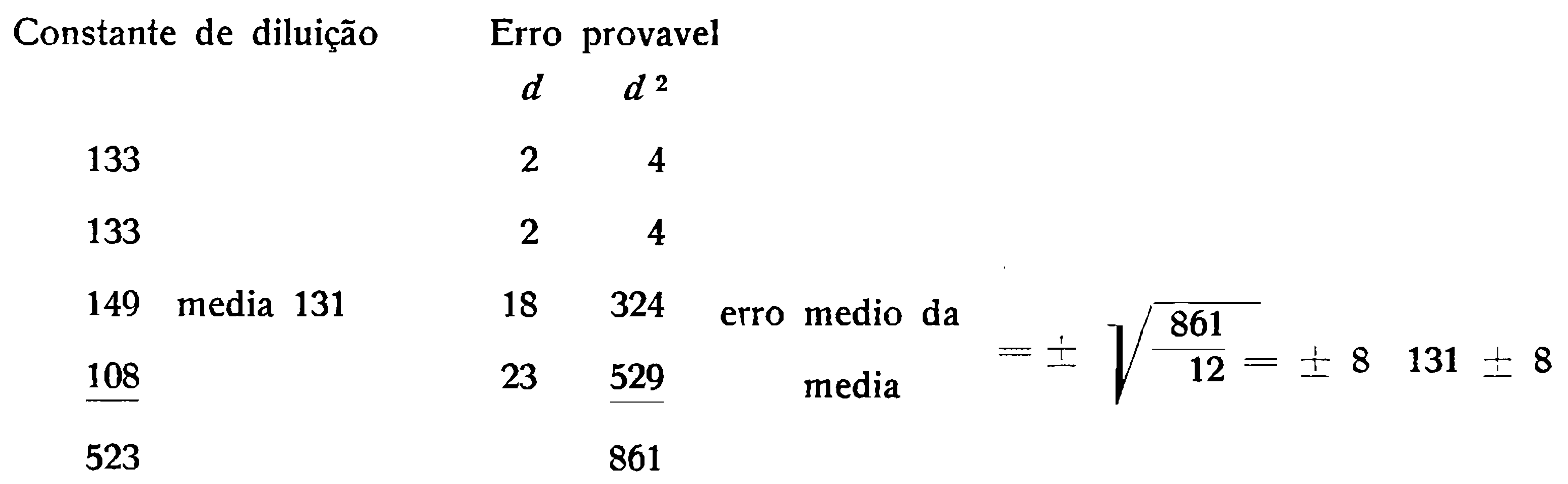

$\begin{array}{lll}\text { Valor calculado } & \text { Valor achado } & \text { Calculo da massa }\end{array}$

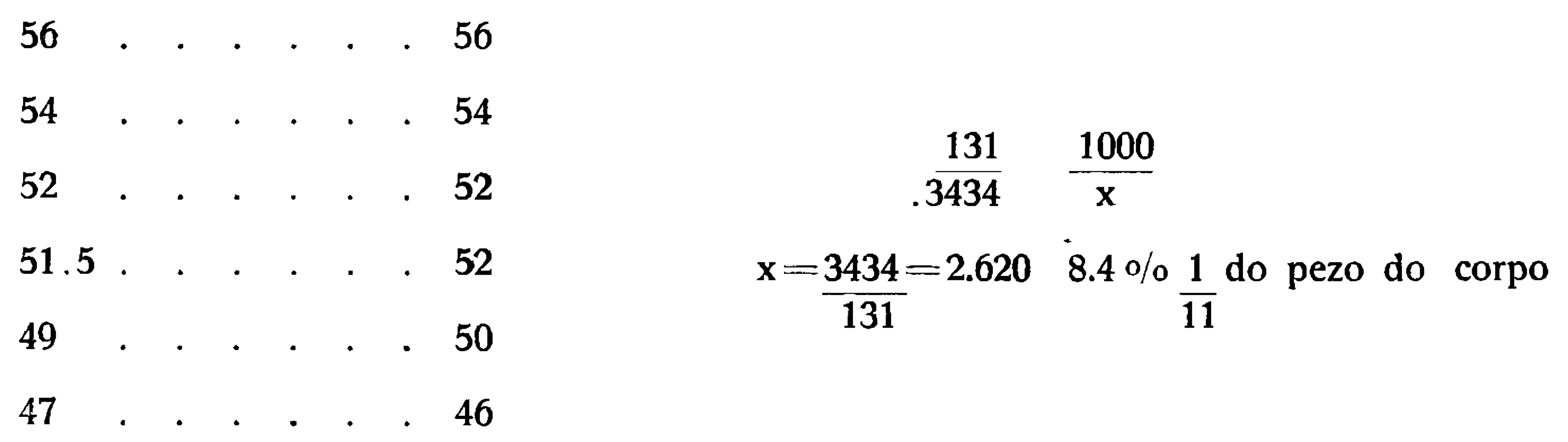

Hund No 1

Konstante der Verduennung Wahrscheinlicher

\section{Fehler}

$$
a^{\prime} \quad d^{2}
$$

$133 \quad 2 \quad 4$

$133 \quad 2 \quad 4$

149 Mittelwert $131 \quad 18 \quad 324$ durchschnittl.

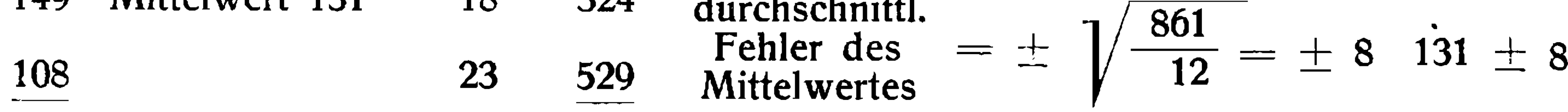

523

861

Berechneter Wert Gefundener Wert Berechnung der Masse 56 . . . . . 56

$54 . . \quad . \quad .54$

$52 . . \quad . \quad .52$

$\frac{131}{.3434} \quad \frac{1000}{x}$

$51.5 . . . \quad . \quad 52$

$x=\frac{3434}{131}=2.620 \quad 8.4 \% \frac{1 \text { des Koerpergewichtes }}{11}$

49 . . . . . 50

47 . . . . . . 46 
Carneiro N.o 1 Pezo $=24$ k. 400 gr. $\quad$ Temp. $=380$

Sangria Quantidade total

$700 \mathrm{cc}$.

Operação

$\frac{112}{812} \gg$ provas

Tempo total

$30^{\prime}$

$\begin{gathered}\text { Reziduo } \\ \text { seco }\end{gathered}$
Cloretos R.s. - Clor. Provas Tempo Calculo da massa

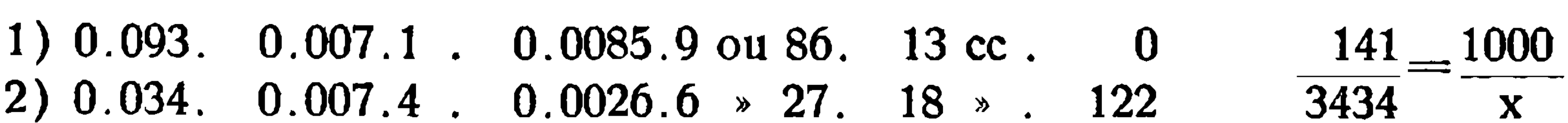

3) $0.039,0.007 .3 \cdot 0.0031 .7,32.20 \%$

Dozajens

4) $0.038 .0 .007 .5 .0 .0030 .5 \gg 30.18 \gg .360$

5) $0.026 .0 .007 .5 \cdot 0.0018 .5 \gg 18.13 » .475$

$x=\frac{3434 \times 1000}{141}=$

6) $0.020 \cdot 0.007 .5 \cdot 0.0013 \quad 13.15 » .589$

7) $0.008 .0 .007 .5 .8 \% .701$

8) $0.018 .0 .007 .6 \cdot 0.0010 . \$ 10.7 \gg .808$

2.435 isto é $9.1 \%$ do pezo do corpo ou

$\frac{1}{11}$

* Foram Constantes de Erro provavel

eliminadas diluição

\begin{tabular}{rrrrl} 
& & $d$ & \multicolumn{1}{c}{$d^{2}$} & \\
178 & & 37 & 1369 & \\
128 & & 13 & 169 & \\
143 & media & 2 & 4 & erro \\
139 & 141 & 2 & 4 & medio da $= \pm \sqrt{\frac{2171}{20}}= \pm 10$ \\
$\frac{116}{706}$ & & 25 & $\frac{625}{2171}$ & media
\end{tabular}

\begin{tabular}{|c|c|}
\hline $\begin{array}{l}\text { Valor } \\
\text { calculado }\end{array}$ & $\begin{array}{r}\text { Valor } \\
\text { achado }\end{array}$ \\
\hline 86 &.$\quad .86$ \\
\hline 39 & 32 \\
\hline 27 & .30 \\
\hline 18 & .18 \\
\hline 13. & . .13 \\
\hline
\end{tabular}

Hammel No 1

Gewicht $=24$ K. 400 Gr.

Temperatur $=380$

Blutentziehung

Versuch Injektion

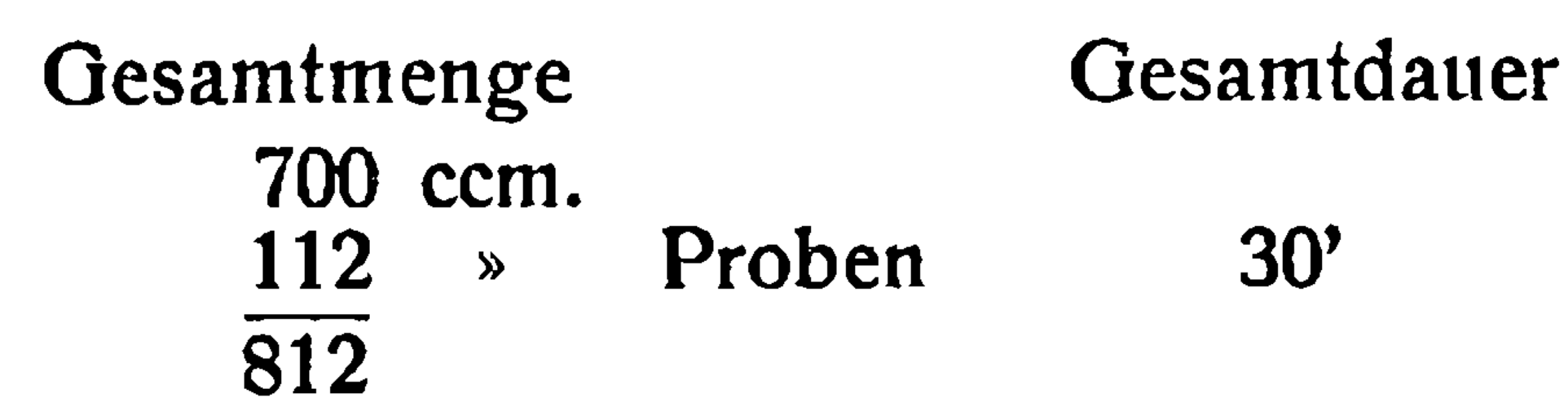

Rueckstand plus

Chlorsalze Proben Dauer

Berechnung

rueckstand Chlorsalze

der Masse

* Nicht beruecksichtigt.

1) 0.093 .0
$*$ 2) 0.034 .0
3) 0.039 .0
4) 0.038 .0$.
5) 0.026 .0
6) 0.020 .0
7) 0.008 .0
* 8) 0.018 .0
ruecksichtigt.
Wahrscheinlicher

Dosierungen

Fehler

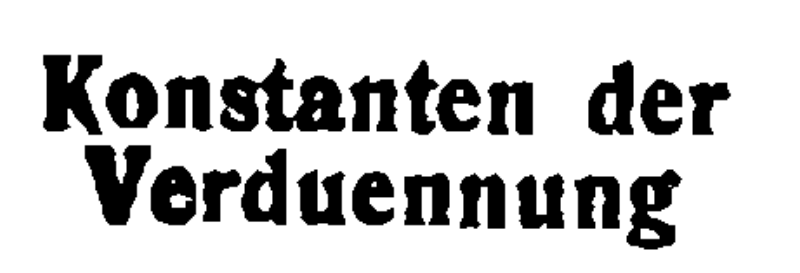

d $\quad d^{2}$

$37 \quad 1369$

143 Mittelwert 2

139141

115

13169 durchschnittl. Fehler

0.0085 .9 ou $86.13 \mathrm{ccm}$. 0

$\overline{706}$

25

$0.0026 .6 \gg 27.18 \gg 122$

0.0031 .7 »32. 20 » 241

$0.0030 .5 \gg 30.18 \gg 360$

$0.0018 .5 \gg 18.13 \gg 475$

$0.0013 \gg 13.15 \gg 589$

$8 \gg 701$

7.6 . 10

$7 \gg 808$

$$
\begin{aligned}
& \frac{141}{3434}=\frac{1000}{x} \\
& x=\frac{3434 \times 1000}{141}= \\
& 2.435=9.1 \% \\
& \text { des Koerper- } \\
& \text { gewichts oder } 1
\end{aligned}
$$

Berechneter Gefundener Wert Wert

86 . . . 86

39 . . 32

27 . . 30

18 . . 18

13 . . 13 
Gato N.o 1 Pezo $=3$ k. 510 gr. $\quad$ Temp. $=3805$

Operação
Sangria

Injeção
Quantid.

135 cc

$\frac{40}{175}$ ce provas

$\begin{array}{ccccc}\text { R. seco } & \text { Cloretos } & \text { R. seco-Clo. } & \text { Tempo Provas } \\ \text { 1a } 0.090 . & 0.008 .6 & 0.0081 . & 0 & 7 \mathrm{cc} .\end{array}$

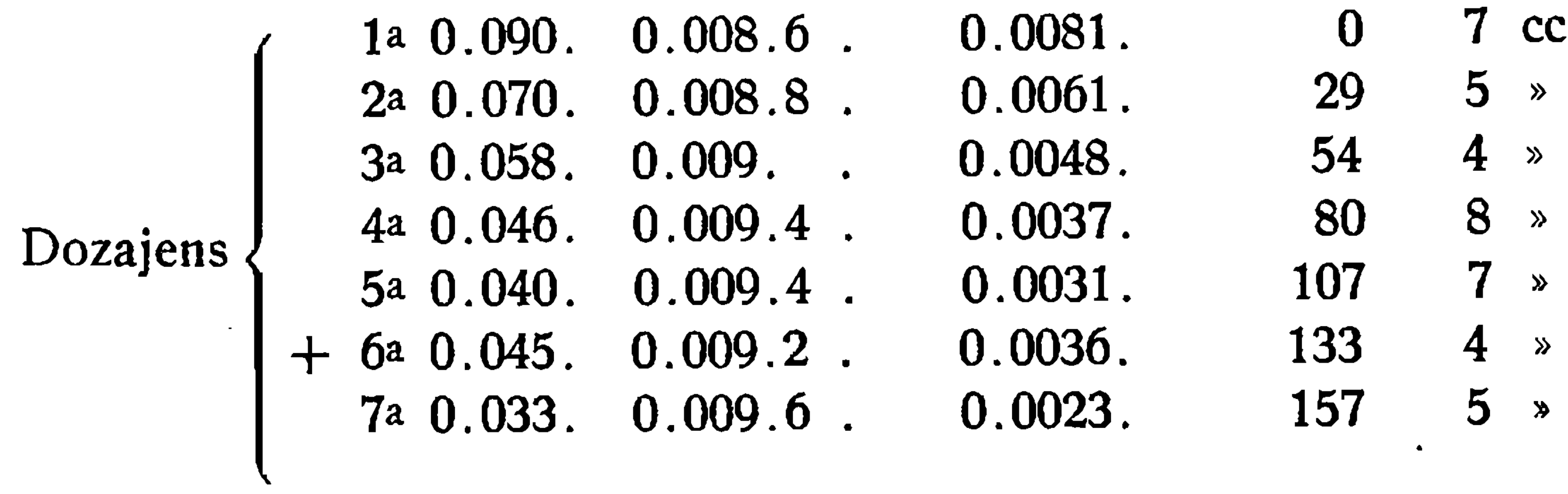

Constantes Erro provavel

diluição de $d \quad d^{2}$

$424 \quad 10 \quad 100$

425 medio $11 \quad 121$

$\begin{array}{lllll}420 & 414 & 6 & 36 & \text { erro }\end{array}$

$\frac{389}{1658} \quad \frac{25}{882}$

625
Tempo total

$20^{\prime}$

Calculo da massa

$\frac{414}{.3434}=\frac{1000}{x}$

$\mathrm{x}=\frac{3434 \times 1000}{414}=$

$829 \mathrm{cc}$ isto é $23 \%$ do pezo do corpo ou $\frac{1}{4.3}$

Valor Valor calculado achado

$81 . . \quad 81$

$61 \cdot . \cdot 61$

$48 . \cdot .48$

38 . . . 37

$29 \cdot . \quad \cdot 31$

$18 \cdot . \div 23$

Nota: a cruz na 6.a prova indica que foi eliminada

Katze No 1

Gewicht $=3$ K. 510 Gr.

Temperatur $=3805$

Versuch

Blutentziehung Gesamtmenge Gesamtdauer

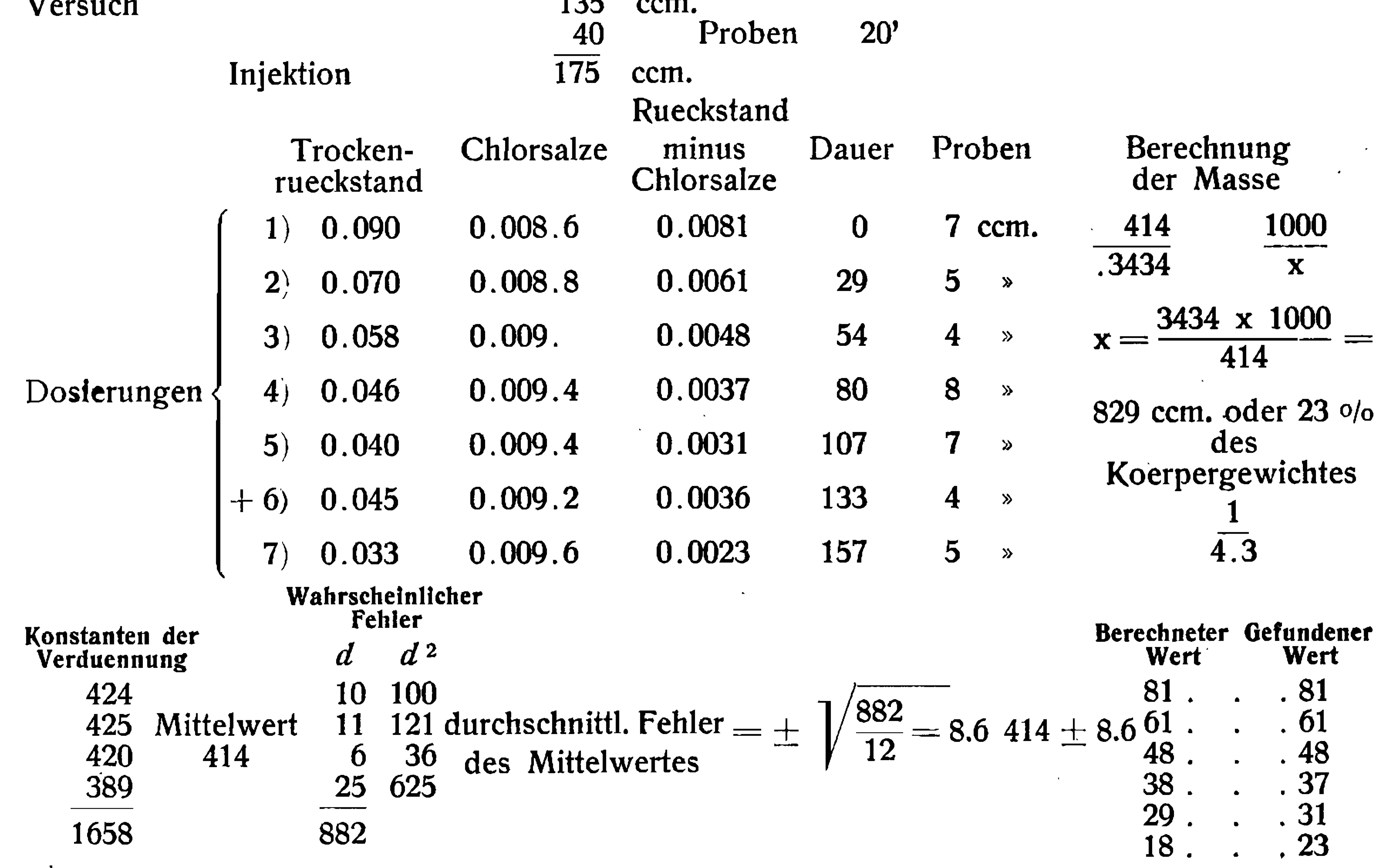

Bemerkungen: Das Kreuz bei der 6. Probe bezeichnet, dass sie ausgeschieden wurde. 


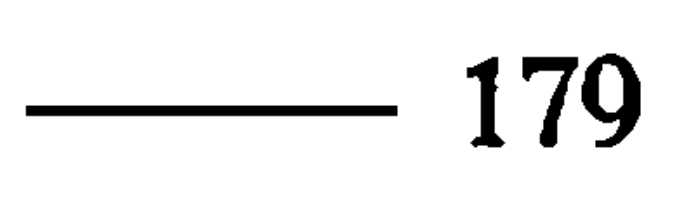

Cavalo N.o $1 \quad$ Pezo $=250$ kilos $\quad$ Temp. $=36$

Operação

Injeção

Sangria Quantidade Tempo

Reziduo

seco Cloretos R. s. - Clorur. Provas Tempo Calculo da massa

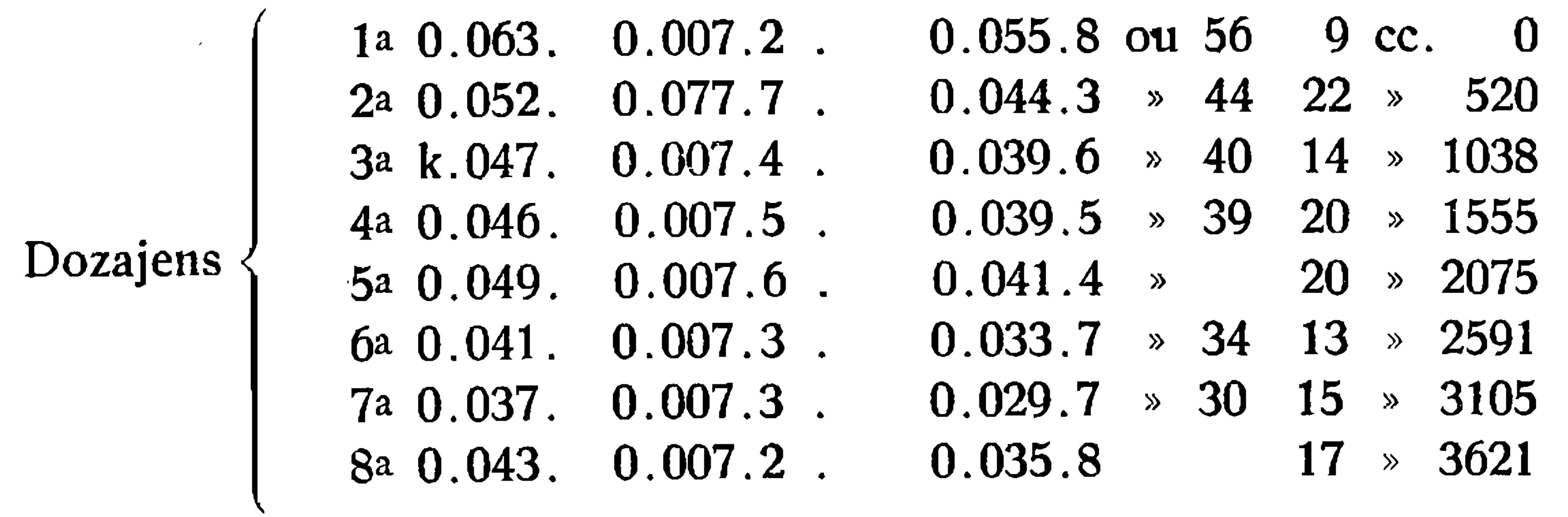
$\begin{aligned} 31500 & \text { gr. } 15^{\prime} \\ 130 & \gg \text { provas }\end{aligned}$ $\overline{3^{1} 630}$

Constante Erro provavel de diluição $\quad d d^{2}$

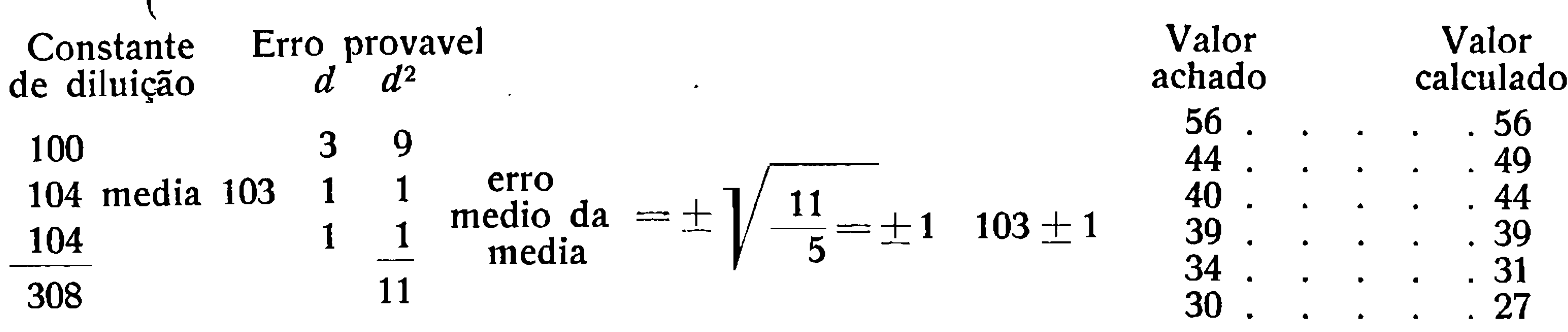

Pferd No 1

Gewicht $=250$ Kilogr.

Berechnung der Masse

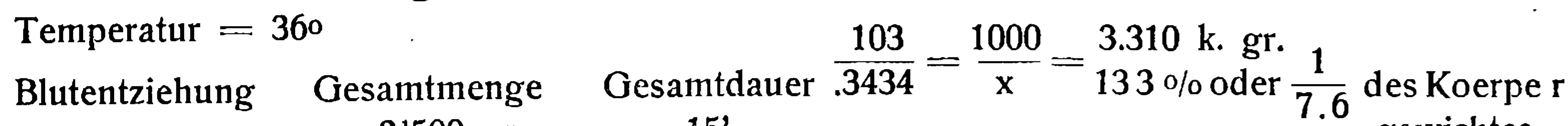

Versuch

Injektion $\quad \overline{3^{1} 630} \mathrm{gr}$.

$31500 \mathrm{gr}$.

$15^{\prime}$

gewichtes

Trocken- Chlorsalze Rueckstand minus

rueckstand Chlorsalze Proben Dauer

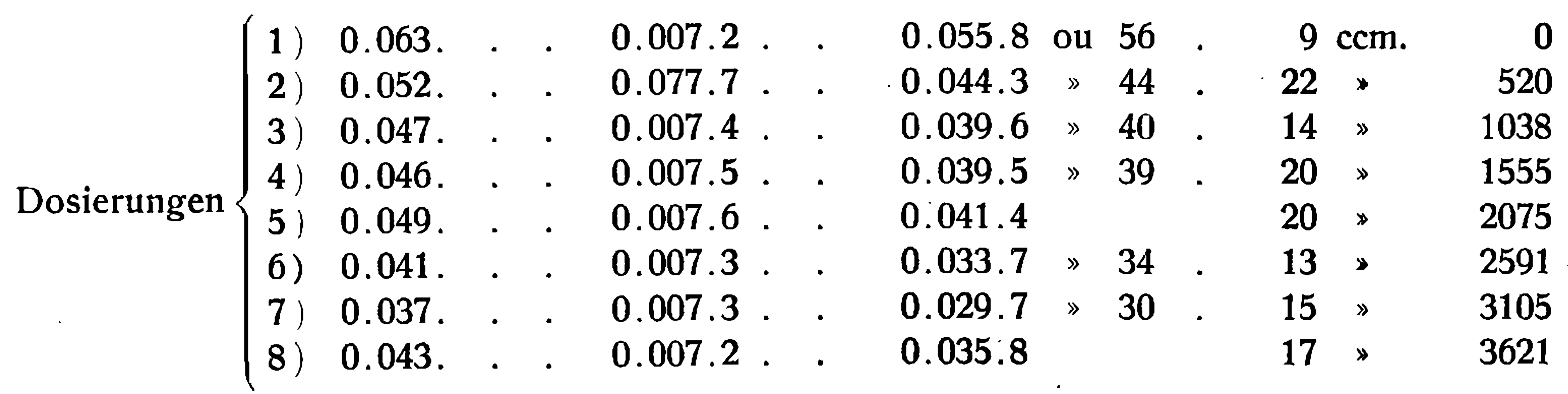

\section{Konstanten der \\ Verduennung}

Wahrscheinlicher

10030

104 Mittelwert 11 durchschnittl. Fehler.

$104 \quad 103 \quad 1 \quad 1$ des Mittelwertes

$\overline{308} \quad \overline{11}$

$$
\begin{gathered}
\frac{103}{.3434}=\frac{1000}{\mathrm{x}} \\
=\mathrm{x} \frac{.3434 \times 1000}{103}= \\
3.310 \mathrm{gr} .133 \% \text { ou } \frac{1}{7.6} \\
\text { do pezo do corpo }
\end{gathered}
$$


Cabra N.o 1 Pezo 24 k. 600 gr. Temp. 4001

Sangria Quantidade Tempo total

Operações

\begin{tabular}{|c|c|c|}
\hline & $\begin{array}{l}800 \mathrm{cc} \\
140 \text { provas }\end{array}$ & $45^{\prime} \quad x=$ \\
\hline njeção & $\overline{940}$ & \\
\hline
\end{tabular}

Reziduo

seco Cloretos R. s. - Clor. Provas Tempo Calculo da massa

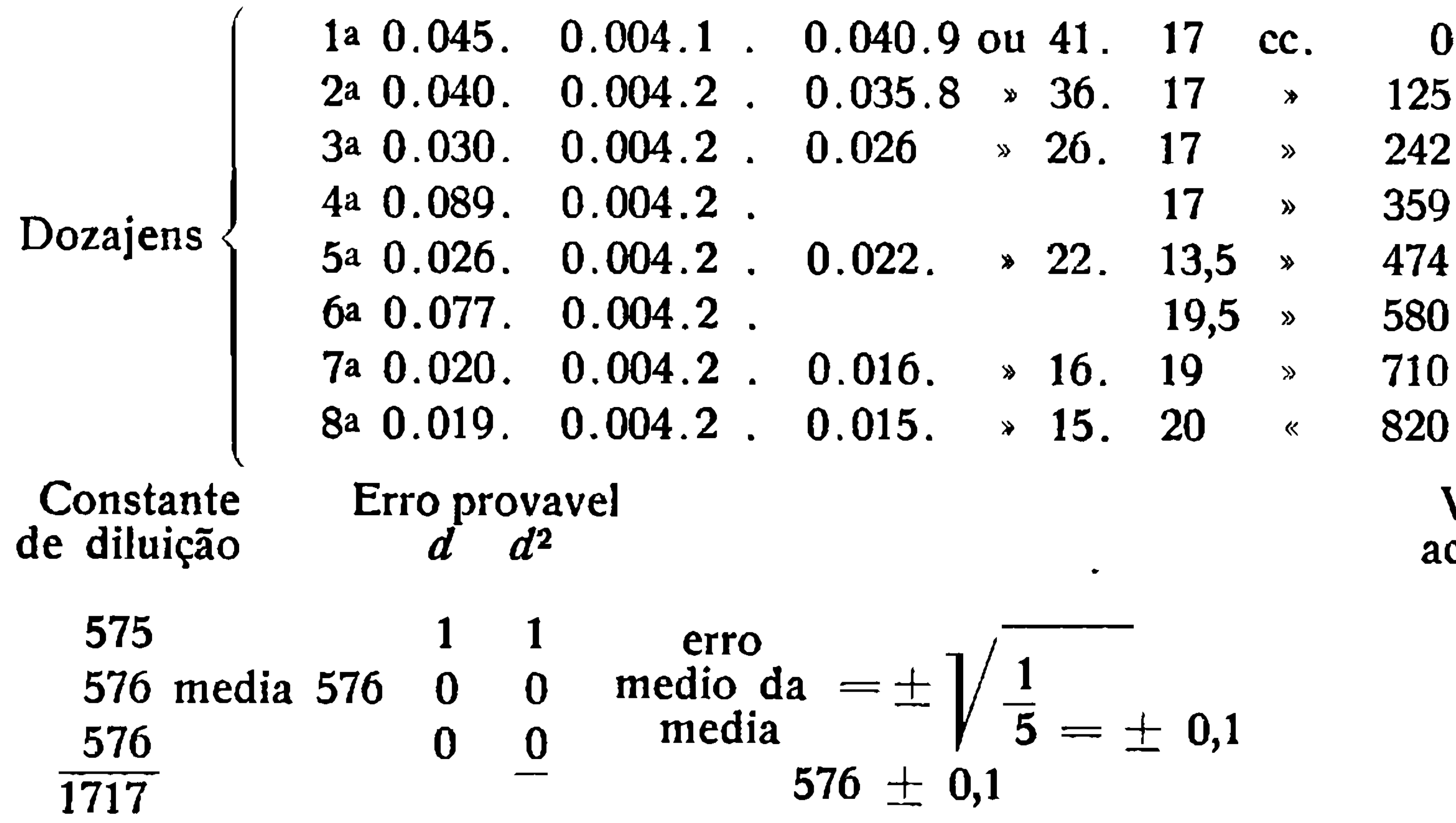

$\begin{array}{llllllllr}\text { 1a } & 0.045 . & 0.004 .1 & 0.040 .9 \text { ou } & 41 . & 17 & \text { cc. } & 0 \\ \text { 2a } & 0.040 . & 0.004 .2 . & 0.035 .8 & \text { \% } 36 . & 17 & * & 125\end{array}$

$19,5 \gg 580$

« 820

$$
\frac{576}{.3434}=\frac{1000}{\mathrm{x}}
$$$$
\mathrm{x}=\frac{.3434 \times 1000}{576}=
$$

$596 \operatorname{cc} 24 \%$ ou $\frac{1}{4.1}$ do

pezo do corpo

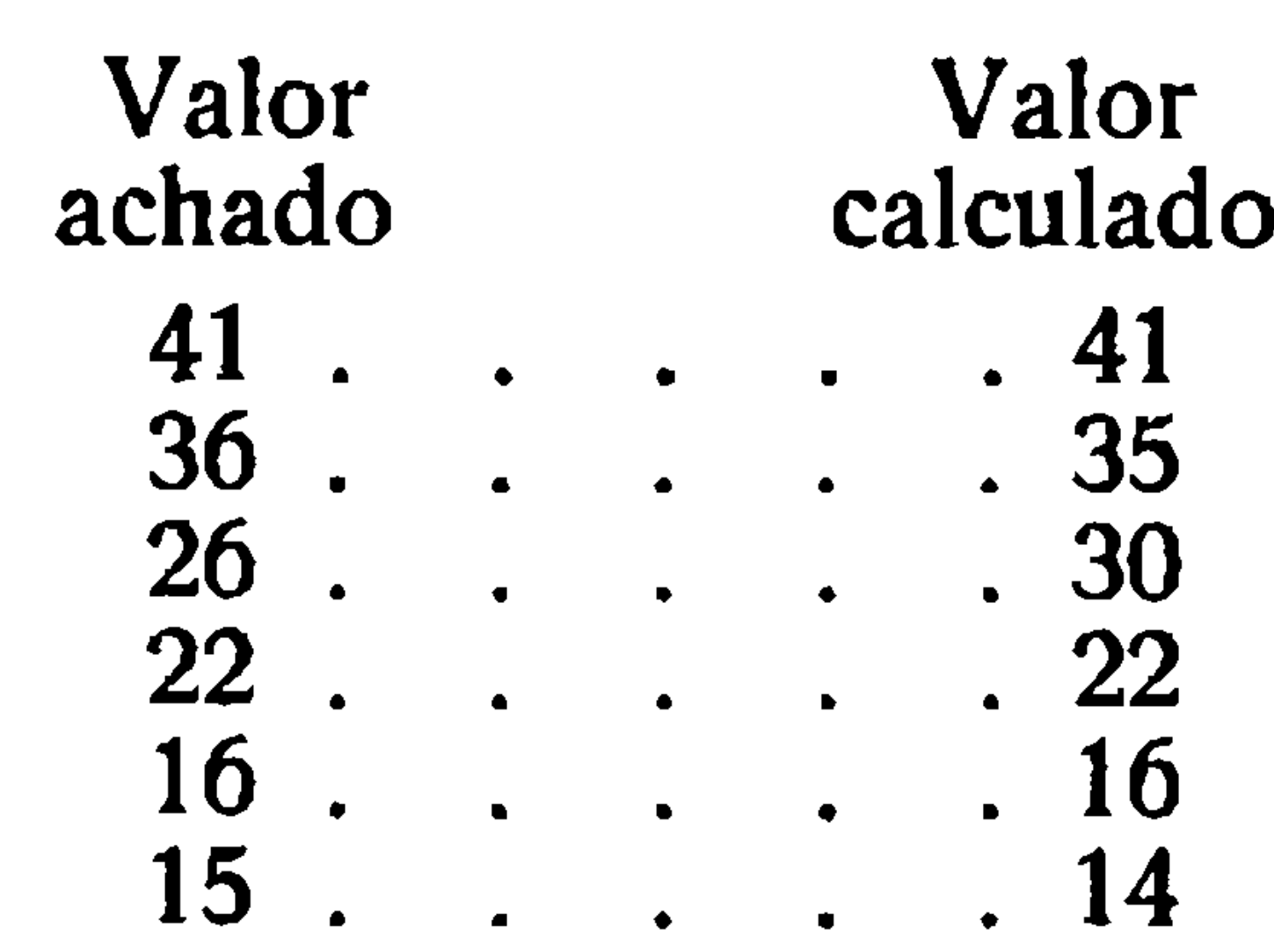

Ziege No 1

Gewicht $=24$ K. 600 Gr.

Temperatur $=4001$

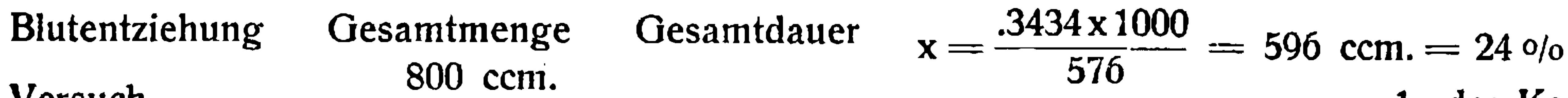

Versuch

Injektion 140 " $>$ Proben 45' $\operatorname{oder} \frac{1}{4.1}$ des Kowichtes

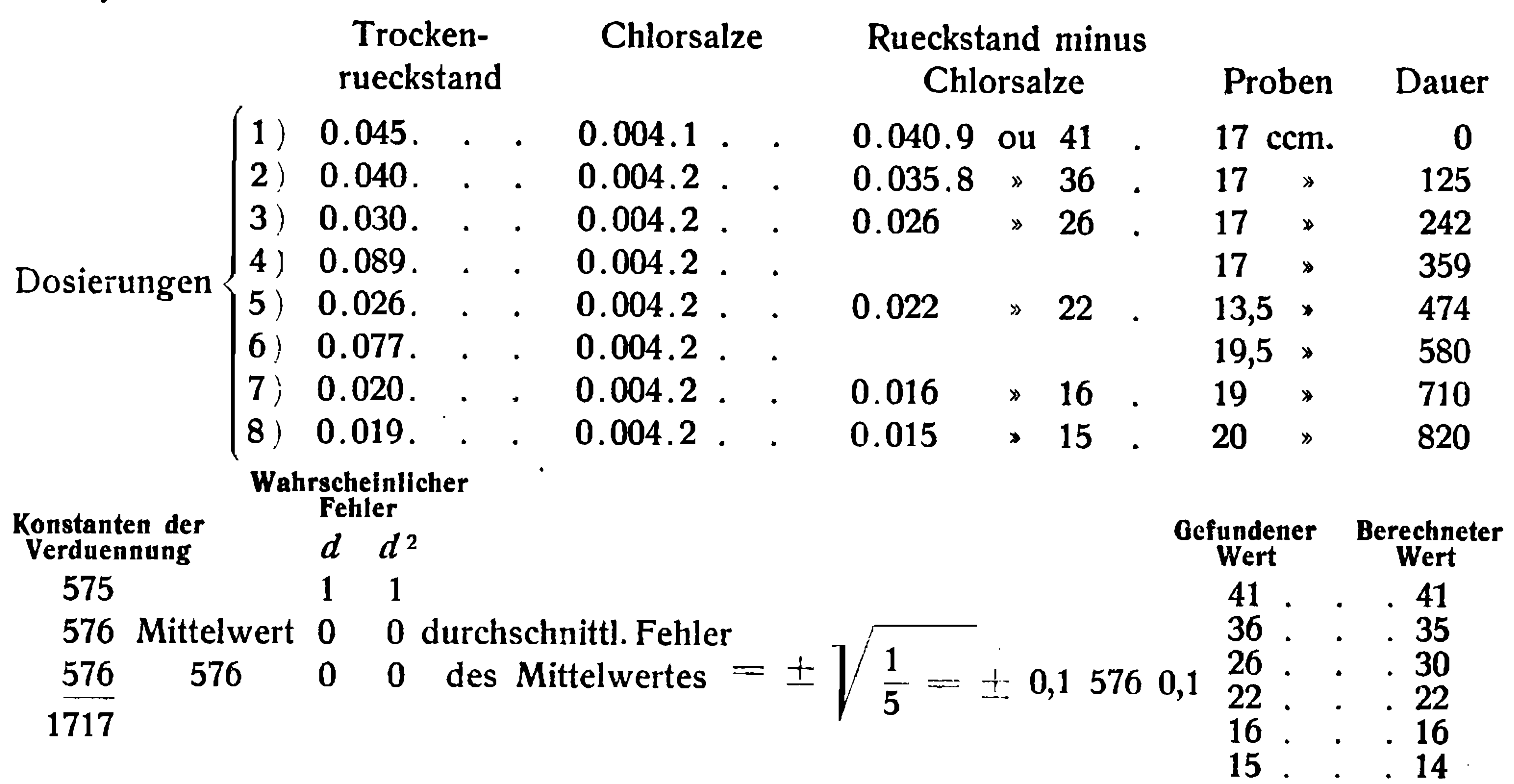


Coelho N.o 1 Pezo $=1$ k. 620 gr. $\quad$ Temp. $=380$

Operações

Sangria

Quantidade t. Tempo total

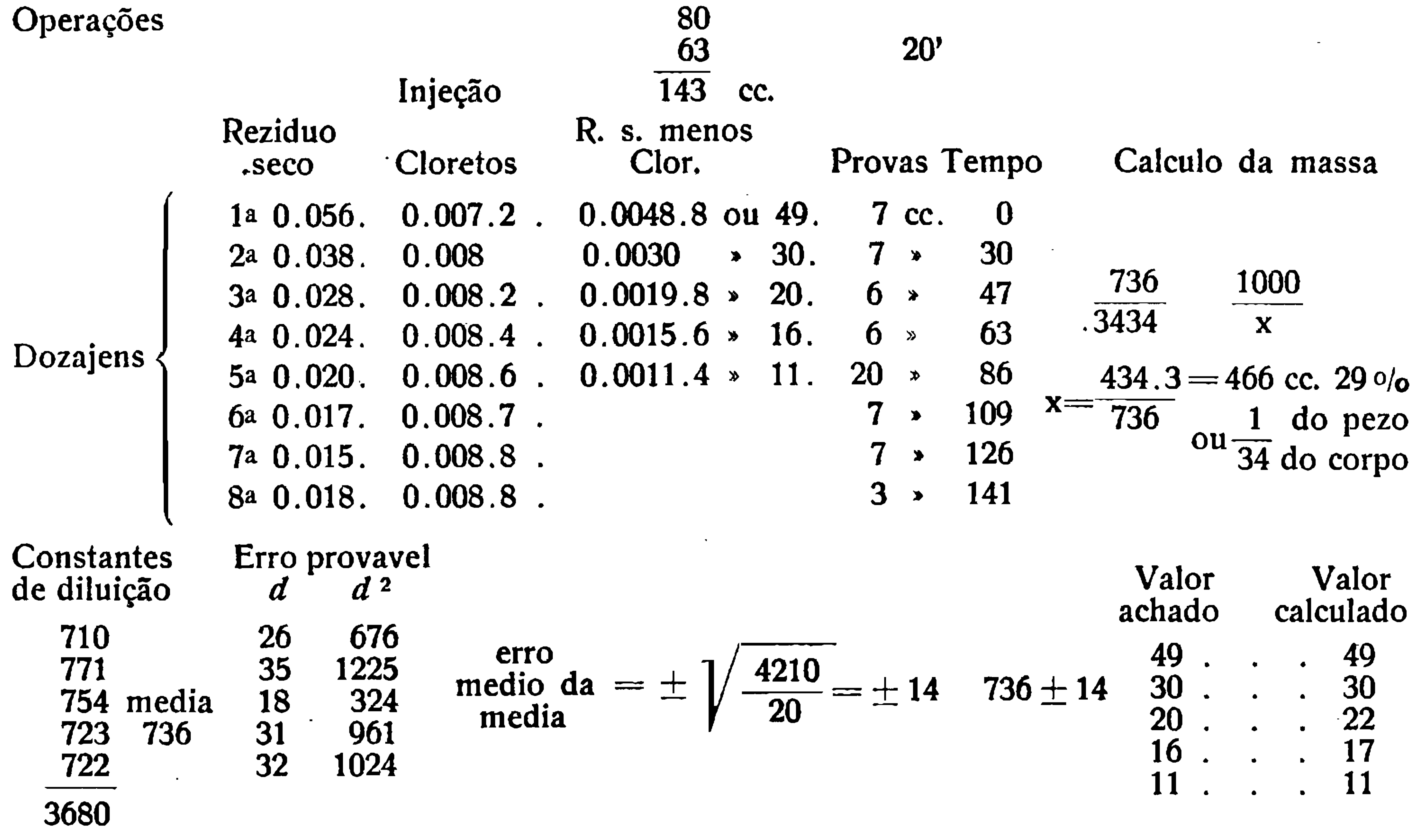

Kaninchen No 1

Gewicht $=1$ K. 620 Gr.

Temperatur $=380$

Blutentziehung Gesamtmenge Gesamtdauer

Versuch

Injektion

80

63

$20^{\prime}$

Berechnung der Masse

Injektion

$143 \mathrm{ccm}$.

Trocken-

rueckstand

Chlorsalze Rueckstand minus

$$
.3 \frac{736}{3434} \quad \frac{1000}{x}
$$

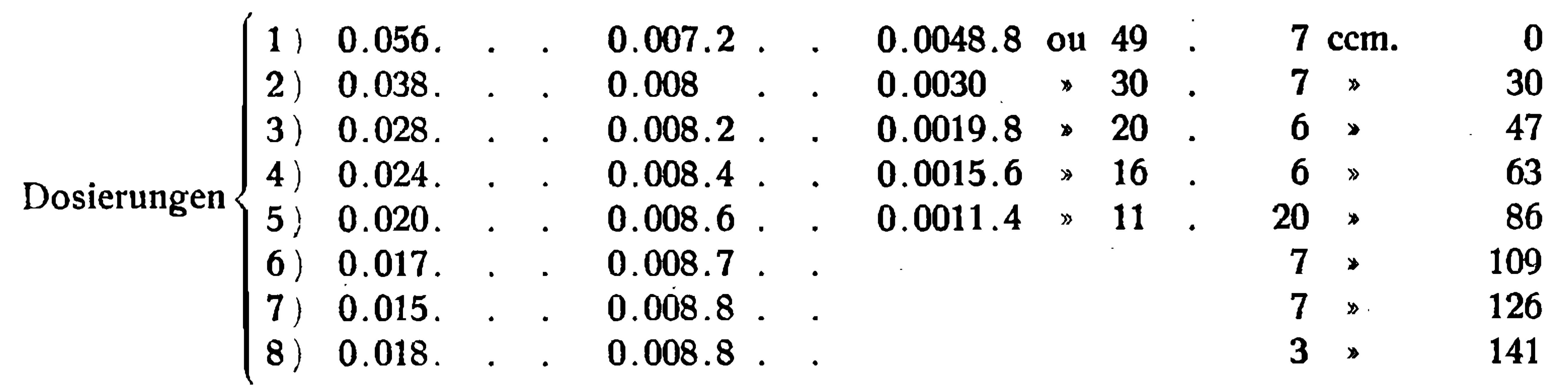

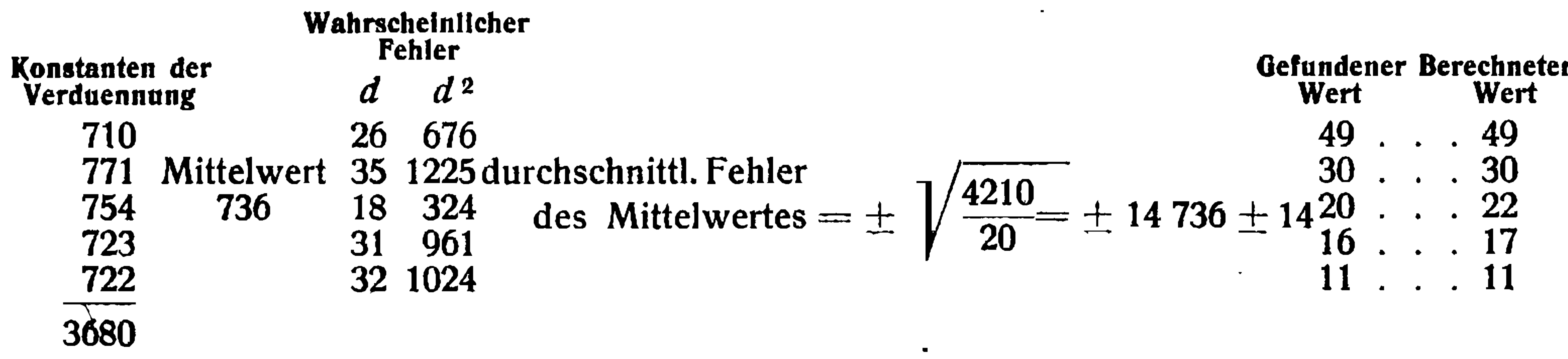


Rezumindo nosso quadro, os rezultados colhidos na serie animal que experimentamos, pode-se avaliar pela comparação as diferenças com as de alguns autores

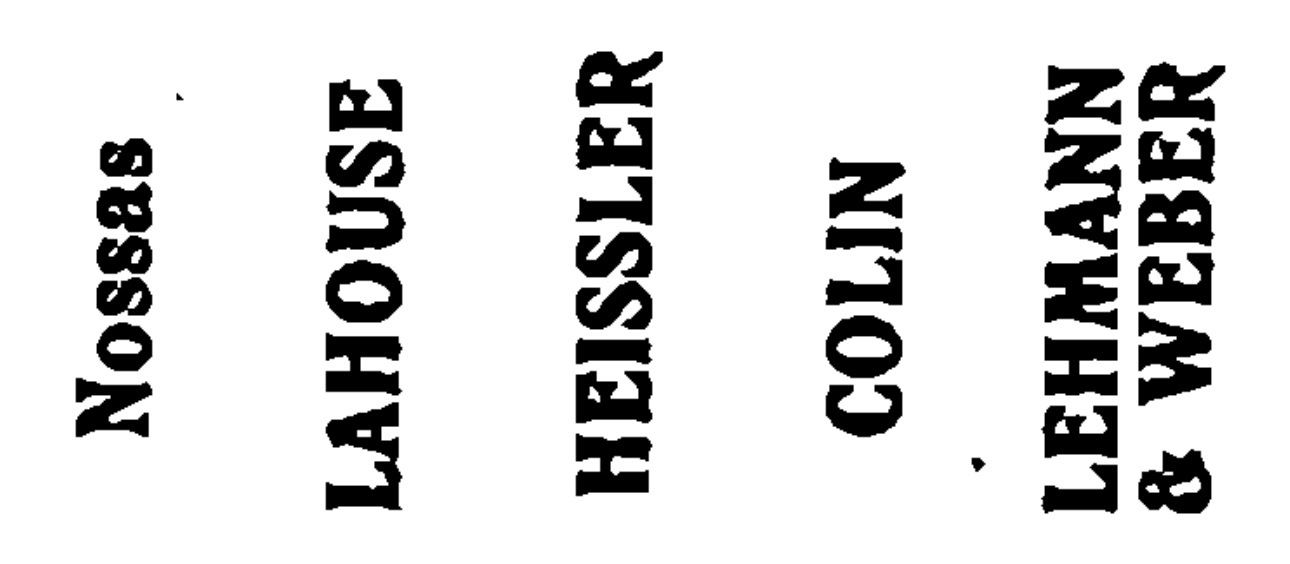

Cão (pezo do corpo) $\frac{1}{11} \quad \frac{1}{13} \quad \frac{1}{11} \quad \frac{1}{17} \quad \frac{1}{16}$

Cavalo » » » $\frac{1}{76} \quad \frac{1}{10} \quad \frac{1}{18} \quad \frac{1}{18}$

Coelho » » $\quad \frac{1}{34} \quad \frac{1}{18} \quad \frac{1}{31} \quad \frac{1}{31}$

$\begin{array}{llllll}\text { Cabra » » } \quad \frac{1}{41} & \frac{1}{12} & \frac{1}{33} & \frac{1}{33}\end{array}$

Gato 》 \ $\quad \begin{array}{rrrr}\frac{1}{10} & \frac{1}{24} & \frac{1}{24}\end{array}$

Estes autores não seguiram metodos identicos no calculo da massa total sanguinea. Dentre os metodos até hoje empregados releva notar o prơcesso das misturas (VALENTIM), em que dozajens do reziduo seco sanguineo normal e determinadamente diluido servem de baze ao calculo da massa numa formula aritmetica sinjela, e o de DREYER e RAY, em que o volume do sangue, sendo uma função da superficie do corpo

é expresso na formula $B=\frac{W \frac{2}{3}}{K}$, onde $B$ é o volume em $\mathrm{cm}$. c., $W$ o pezo em gramas, $\mathrm{K}$ uma constante, calculada pelas experiencias e variando para cada especie.

Terminando cumpre agradecermos ao ilustre Dr. OSWALDO CRUZ, a gentileza do acolhimento dispensado, e os esclarecidos conselhos durante nosso trabalno. Ao Dr. ALCIDES GODOY, guia e inspirador das nossas pesquizas, o auxilio diario dos seus ensinamentos, sem os quais os nossos rezultados seriam apenas os dum esforço baldado.

Manguinhos, 1 de Maio de 1912.
Wenn wir die auf unseren Tabellen aufgefuehrten, in der untersuchten Tierreihe erlangten Resultate zusammenfassen, koennen wir vergleichsweise die mit den Ergebnissen mancher Autoren bestehenden Unterschiede abschaetzen.

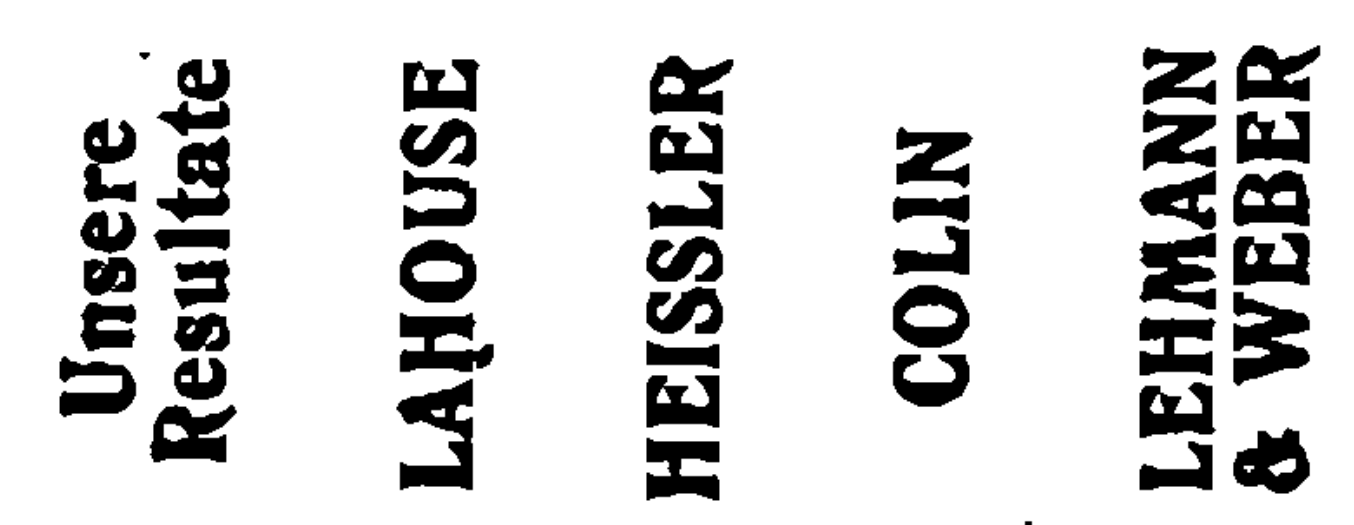

$\begin{array}{llllll}\text { Hund (Koerpergewicht) } & \frac{1}{11} & \frac{1}{13} & \frac{1}{11} & \frac{1}{17} & \frac{1}{16}\end{array}$

\begin{tabular}{|c|c|c|c|c|c|c|}
\hline & & 1 & & 1 & 1 & \\
\hline Ptera & * & 76 & & 10 & $\overline{\mathbf{1 8}}$ & 18 \\
\hline Kaninchen & & 1 & 1 & & 1 & 1 \\
\hline Samminten & 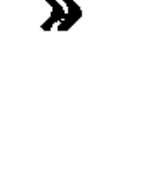 & 34 & 18 & & 31 & 31 \\
\hline & & 1 & & 1 & 1 & \\
\hline Ziege & » & 41 & & $\overline{12}$ & $\overline{33}$ & 33 \\
\hline Katze & $\gg$ & $\frac{1}{10}$ & & & $\frac{1}{01}$ & $\frac{1}{24}$ \\
\hline & & 10 & & & 24 & \\
\hline
\end{tabular}

Obige Autoren gingen nicht nach gleichen Methoden bei der Berechnung der Gesamtblutmasse vor. Von diesen Methoden verdienit das Verfahren der Mischungen (VALENTIN) hervorgehoben zu werden, bei welchem die Berechnung der Blutmasse mit Hilfe einer einfachen arithmetischen Formel auf Dosierungen des normalen Trockenrueckstandes und des in bestimmter Weise verduennten Rueckstandes des Blutes beruht und diejenige von DREYER und RAY, bei welcher das Volumen des Blutes eine Funktion der Koerperflaeche ist; dasselbe wird ausgedrueckt in der Formel: $B=\frac{W^{\frac{2}{3}}}{\dot{K}}$, in welcher $B$ das Volumen in Kzm., $W$ das Gewicht in Grammen und $K$ eine Konstante ist, welche aus den Versuchen berechnet wird und fuer jede Art wechselt.

Zum Schlusse erachten wir es als unsere Pflicht, dem hochverehrten Herrn OSWALDO CRUZ fuer die uns gewaehrte freundliche Aufnahme im Institut und fuer die gewichtigen Ratschlaege waehrend dieser Arbeit, unseren Dank auszudruecken. Wir danken ferner Herrn Dr. ALCIDES GODOY, den Leiter und geistigen Fuehrer bei unseren Versuchen, der uns taeglich mit seinen Weisungen zur Seite stand und ohne welchen unsere Arbeiten gescheitert waeren.

Manguinhos, den 1. Mái 1912. 


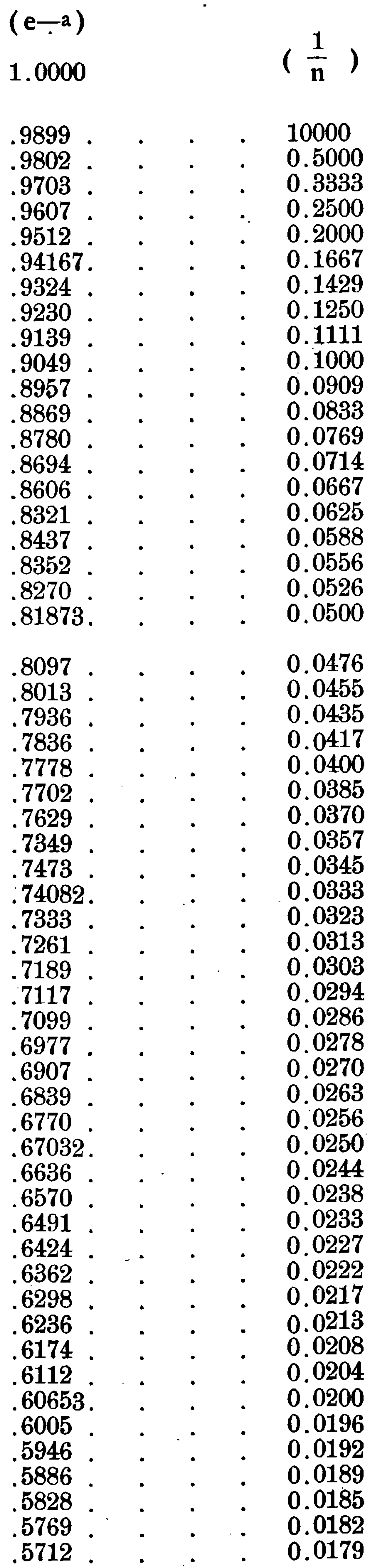

.5650 . . . . 0.0175

$.5599 . \quad \cdot \quad \cdot \quad 0.0172$

.5544 . . . . 0.0169

$.54881 . \quad .0 .0167$

$.5434 . \quad . \quad .0 .0164$

$.5379 . \quad . \quad . \quad . \quad 0.0161$

$5326 . \quad . \quad .0 .0159$

$.5272 . \quad . \quad .0 .0156$

$5220 . \quad . \quad .0 .0154$

$.5169 . \quad . \quad 0.0152$

$.5117 . \quad . \quad . \quad . \quad 0.0149$

$.5066 . \quad . \quad 0.0147$

$5015 . \quad . \quad .0 .0145$

.49639 . . . . 0.0143

.4916 . . . 0.0141

$4867 \quad 0.0139$

.4817 . . . 0.0137

$4771 \quad 0.0135$

$4724 . \quad . \quad 0.0133$

(80)

$4677 . \quad \cdot \quad . \quad 0.0132$

$4630 \quad-\quad 0.0130$

$4385 . \quad . \quad .0 .0128$

.4338 . $. \quad . \quad 0.0127$

$44933 . \quad . \quad .0 .0125$

$.4448 . \quad . \quad .0 .0123$

.4404 . . . . 0.0122

$4360 \div \quad . \quad 0.0120$

$.4317 \div \quad . \quad . \quad 0.0119$

.4274 . . . 0.0118

$4232 \cdot \quad . \quad 0.0116$

(70)

$.4190 \div \quad \cdot \quad . \quad 0.0115$

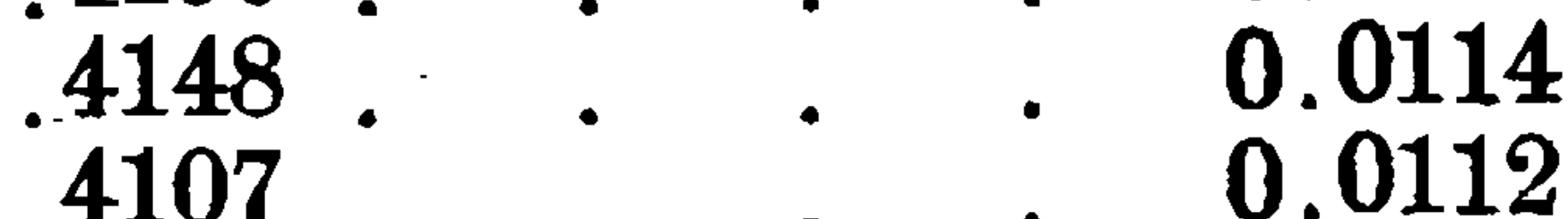

$.40657 . \quad \cdot \quad \cdot \quad 0.0111$

(10)

$.4025 \cdot \div: \div 0.0109$

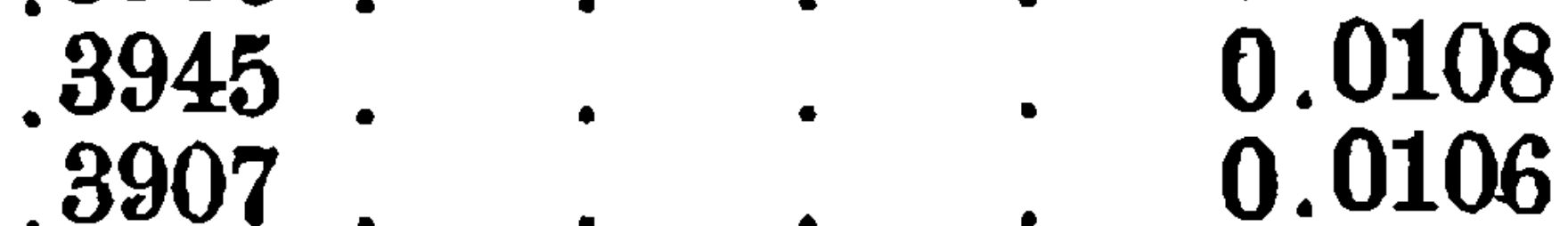

$3867 \div \quad \cdot \quad \cdot 0.0105$

$.3821 . \quad . \quad 0.0104$

$3791 \quad 0.0103$

(60)

.3733

0.0102

$3716 \div 0.0101$

(40)

(30)

$.36788 . \quad . \quad .0 .0100$

(50) 


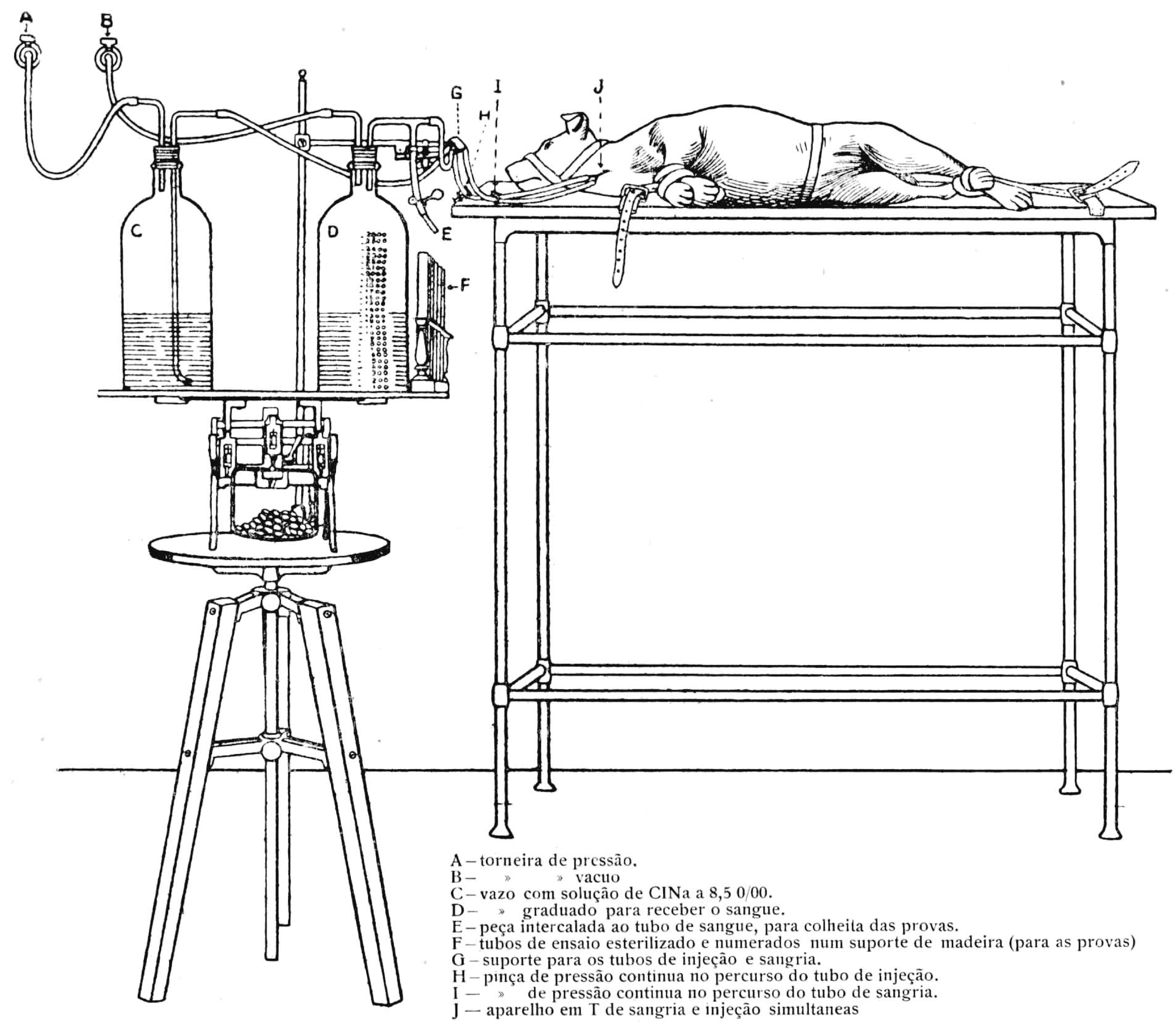

- prça de pressáo continua no percurso do tubo de injeção.

I - " de pressão continua no percurso do tubo d 


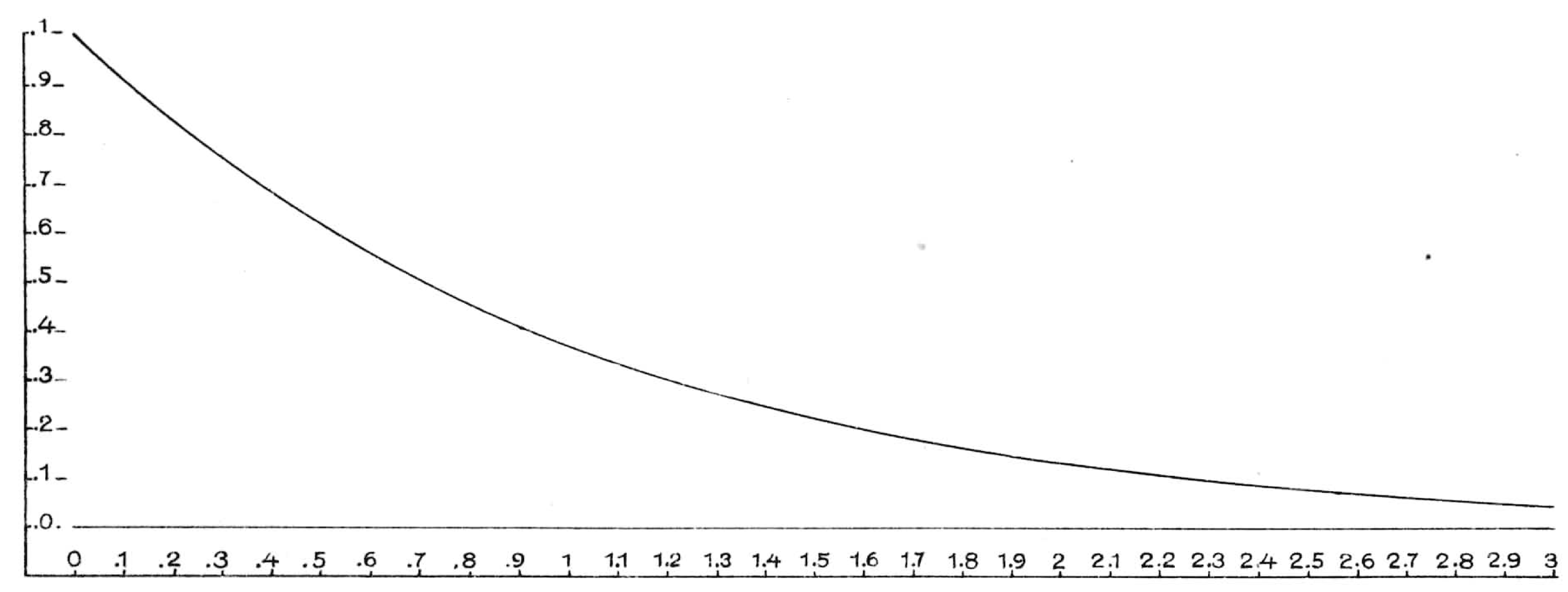

